\title{
EVALUATION OF REGION AND SUBREGION-BASED HEIGHT- DIAMETER MODELS FOR DAHURIAN LARCH (LARIX GMELINII) IN DAXING'AN MOUNTAINS IN CHINA
}

\author{
ENZINGA, G. Y. ${ }^{1}-$ JIANG, L.-C. ${ }^{2 *}$ \\ ${ }^{l}$ Forest Management Department, College of Forestry, Hexing Road, Xiangfang District, \\ 150040 Harbin, China \\ ${ }^{2}$ Northeast Forestry University, Harbin, Heilongjiang Province, China \\ *Corresponding author \\ e-mail: jlichun@nefu.edu.cn
}

(Received $4^{\text {th }}$ Apr 2019; accepted $31^{\text {st }}$ Oct 2019)

\begin{abstract}
Using the felled tree data, subregions-based height-diameter models were developed for Dahurian larch (Larix gmelinii Rupr) in Daxing'an Mountains in China. Thirty frequently used nonlinear growth functions were fitted to individual tree height-diameter data. A total of 2411 for Dahurian larch trees were collected and measured. Parameter estimates and evaluation statistics were calculated using SAS PROC NLIN procedure for overall model, three regional models, and ten subregional models. The non-linear extra sum of squares method was used to assimilate the difference of the height-diameter relationships among different subregions. The results indicate that the Chapman-Richards growth function show the best for fitting tree height-diameter relationships at regional and subregional levels with a root mean square error $\mathrm{RMSE}=2.193$ and coefficient determination $\mathrm{R}^{2}=0.8221$. It was revealed that, Dahurian larch height-diameter relationships showed the several differences among these regions and subregions $(P<0.0001)$ when overall, regional and subregional model was applied to predict tree height separately in each region and subregion. Among the 45 pairs of subregions, only four subregion pairs (e.g., XL versus SBZ, XL versus HJY, SBZ versus HJY, and XL versus JGDQ) showed the nonsignificant difference $\mathrm{F}$-value $(\mathrm{P}>0.05)$ and the data from those subregions were combined and applied to others subregions; all comparisons show the difference. The tree height-diameter relationships of Dahurian larch are significantly different among the geographic regions in Daxing'an Mountains, depending on local climatic, soil, and ecological conditions.
\end{abstract}

Keywords: Chapman-Richards model, non-linear extra sum of square method, full model, reduced model, forest management

\section{Introduction}

Individual tree diameter at breast height (D) and total height are the most fluently measured variables in study of forest inventory and growth and yield modeling. In practice, tree diameters can be readily measured inexpensively. However, collect tree height data are fairly more difficult and expensively. Often total tree heights are obtained by estimations from observed tree diameter at breast height outside bark. To estimate individual tree volume and site index, and describe stand growth dynamics and succession over time, necessitates accurate height-diameter models (Botkin et al., 1972; Curtis, 1967). Particularly in the northern and northeastern provinces of China, the genus Dahurian larch (Larix gmelinii Rupr.) is economically and ecologically important for tree species in China (Leng et al., 2008). Dahurian forests cover an area and volume in the forests of these provinces of 92.9 and 87.6 percent, respectively, of the total Dahurian in the country (Zang et al., 2016). It is a deciduous needle leaf conifer that is adapted to growing in very harsh climates and is widely distributed over a range from $72^{\circ} 31^{\prime} \mathrm{N}$ $105^{\circ} 03^{\prime}$ E. In the Daxing'an Mountains forest ecosystem in northern China, it is the 
dominant tree species (Jiang et al., 2016). Recently, Dai and Jiang (2015) developed and evaluated 12 non-linear height-diameter models for Dahurian larch from three regions in Daxing'an Mountain of northeast China. They found that the Chapman-Richards function was one of the best models for this species across the study region. In this study, we will develop and evaluate 30 nonlinear diameter models for Dahurian larch in three regions subdivided into 10 subregions and we will select the best model according to the goodness-of-fit statistics. With a large number of models, we could expect that the best model for Dahurian larch could be other that of Chapman-Richards as found to the study quoted above. However, if another model is found better than for Chapman Richard; then this will lead us to understand that the Chapman-Richards is not the best suitable model for the Dahurian larch in the Daxing'an mountain, so there is another model better than this one. However, the height-diameter relationship of a given species is highly dependent on climatic patterns (e.g., temperature and precipitation). Application of regional models to local ecological sites may lead to biased predictions for tree heights knowing that these subregions are specified by climatic regimes (e.g. temperature and precipitation), soil moisture and nutrient regimes, and vegetation types. The variations are expected during their comparisons. Examples of models that represent such variation are found (Zhang et al., 2002; Özçelik et al., 2014; Huang, 1999; Huang et al., 1999, 2000; Huang and Titus, 1994; Peng et al., 2001 Pillsbury et al., 1995).

In recent years, the principles of multifunction, multipurpose and ecologically based forest management were approved in China. Therefore, in order to help forest managers and practitioners more realize the differences in these relationships among different subregions, the subregion-based height-diameter models are necessary. to: (1) evaluate tree height-diameter models for Dahurian larch at regional and subregional scales in Daxing'an Mountains at Northeast China; (2) establish the comparison of differences of the height-diameter relationships among the ten subregions; (3) evaluate the consequences and biases of incorrectly applying regional and subregional heightdiameters models in different subregions.

\section{Materials and methods}

\section{Study area and data}

The study area is the cold temperate forest regions in Daxing'an Mountain in Heilongjiang Province and eastern part of Inner Mongolia, from $121^{\circ} 12^{\prime} \mathrm{E}$ to $127^{\circ} 00^{\prime} \mathrm{E}$ and from $50^{\circ} 10^{\prime} \mathrm{N}$ to $53^{\circ} 33^{\prime} \mathrm{N}$ in Northeastern China. The climate is continental monsoon climate. The average annual precipitation ranges from 500 to $750 \mathrm{~mm}$. The mean annual temperature is between -1 and $-2.8{ }^{\circ} \mathrm{C}$, and the average January and July air temperatures are about $-28{ }^{\circ} \mathrm{C}$ and $+20{ }^{\circ} \mathrm{C}$, respectively (Table 1). The study area was assigned to three distinct regions (Zhang et al., 1992): the eastern slope of Northern part of Daxing'an Mountains (NDXAM), the northwest of the northern slope of Yilehuli Mountains (NWYLHLM), and the southeast of the northern slope of Yilehuli Mountains (SAYLHLM). Sample trees were assigned to ten subregions in NWYLHLM, SAYLHLM, and NDXAM regions (Fig. 1). The NWYLHLM region covers four subregions, including Xilinji (XLJ), Tuqiang (TQ), Amuer (AME), Huzhong (HZ); The SAYLHLM region covers four subregions, including Xinlin (XL), Tahe (TH), Shibazhan (SBZ), Hanjiayuan (HJY); the NDXAM region covers two subregions, including Songling (SL), Jiagedaqi (JGDQ). These subregions are specified by climatic schemes (e.g., temperature and precipitation), soil moisture and nutrient regimes, and vegetation types. 


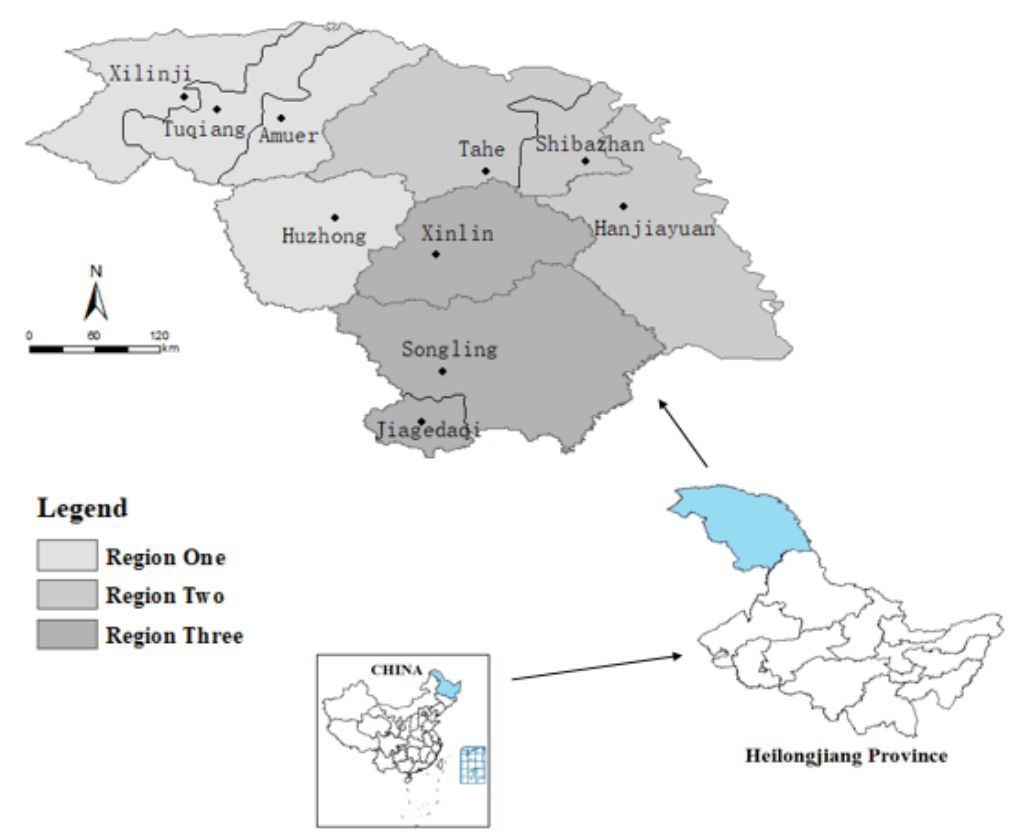

Figure 1. Simple map of ecoregion classification of study area in the Northeast, China

Table 1. Summary of climatic variables

\begin{tabular}{c|c|c}
\hline Subregions & AMT $(\mathbf{C})$ & AMP $(\mathbf{m m})$ \\
\hline SL & -3 & 600 \\
JGDQ & -1.2 & 450 \\
XL & -2.6 & 514 \\
TH & -2.4 & 463 \\
HZ & -4.3 & 498 \\
SBZ & -2.5 & 471 \\
HJY & -2 & 510 \\
XLJ & -7.5 & 500 \\
TQ & -5.5 & 460 \\
AME & -5 & 455 \\
\hline
\end{tabular}

AMT - annual mean temperature; AMP - annual mean precipitation

A total of 2411 destructively sampled Dahurian larch trees were used in this study. These trees were felled throughout the forest inventory areas of northeast China and all sampled trees were selected to ensure a representative distribution across a range of height and diameter classes within stands varying in density, height, site condition, age and stand structure. The data is from an existing database, and was collected from December 2004 and February 2005. For developing taper and individual tree volume equations the data set was initially used. Diameters at breast height were measured for all sampled trees (D, defined as $1.3 \mathrm{~m}$ above the ground) outside bark, and total height $(\mathrm{H})$. Trees possessing broken tops, obvious cankers or crooked boles were excluded from the analysis. Summary statistics for tree diameter and total height are provided for each subregion, the NDXAM, YLHLM-NW and YLHLM-SA regions, and all data combined (Overall) in Table 2. 


$$
-13570 \text { - }
$$

Table 2. Summary of tree diameter at breast height $(D)$ and total height $(H)$ for subregional and regional data sets

\begin{tabular}{c|c|c|c|c|c|c|c|c|c}
\hline \multirow{2}{*}{ Subregion } & \multirow{2}{*}{$\mathbf{N}$} & \multicolumn{5}{|c|}{ D (cm) } & \multicolumn{4}{|c}{ H (m) } \\
\cline { 3 - 9 } & & Mean & STD & Min & Max & Mean & STD & Min & Max \\
\hline SL & 214 & 29.15 & 14.07 & 5.5 & 55.1 & 19.59 & 5.41 & 7.1 & 29.2 \\
JGDQ & 524 & 27.27 & 13.24 & 5.4 & 61.0 & 18.3 & 4.83 & 6.4 & 30.8 \\
XL & 190 & 30.94 & 12.57 & 6.0 & 63.4 & 19.34 & 3.99 & 8.4 & 29.5 \\
TH & 203 & 21.98 & 12.32 & 5.2 & 50.6 & 15.34 & 5.37 & 5.1 & 26.5 \\
HZ & 215 & 23.53 & 11.61 & 5.1 & 48.8 & 16.13 & 4.69 & 4.5 & 25.9 \\
SBZ & 237 & 27.46 & 13.33 & 5.4 & 56.6 & 17.93 & 4.72 & 6.1 & 26.1 \\
HJY & 128 & 26.79 & 12.38 & 5.2 & 50.8 & 17.72 & 4.60 & 6.6 & 26.5 \\
XLJ & 224 & 16.00 & 9.00 & 5.1 & 62.0 & 15.76 & 4.21 & 7.2 & 24.6 \\
TQ & 191 & 23.98 & 14.59 & 5.2 & 56.0 & 17.45 & 5.25 & 6.5 & 28.5 \\
AME & 285 & 33.68 & 13.00 & 5.1 & 72.2 & 22.37 & 4.87 & 7.3 & 33.9 \\
NWYLHLM & 915 & 24.94 & 13.86 & 5.1 & 72.2 & 18.26 & 5.53 & 4.5 & 34.0 \\
SAYLHLM & 758 & 26.75 & 13.10 & 5.2 & 63.4 & 17.56 & 4.93 & 5.1 & 29.5 \\
NDXAM & 738 & 27.82 & 13.50 & 5.4 & 61.0 & 18.67 & 5.03 & 6.4 & 30.8 \\
Overall & 2411 & 26.39 & 13.57 & 5.1 & 72.2 & 18.16 & 5.21 & 4.5 & 34.0 \\
\hline
\end{tabular}

$\mathrm{N}$ - sample size (number of trees), STD - standard deviation, Min. - minimum, Max. - maximum

\section{Data analysis}

The 30 height-diameter equations listed in Fang and Bailey (1998), Huang et al. (2000, 1992) and Peng et al. (2001) were examined and evaluated to select the best model for further analyses. The equations chosen for the comparison were concentrated on the verification of the height-diameter relationship, as shown by plotting tree height against D on a provincial basis (Huang, 1999). All selected functions are shown in Table 3. The validity of a homogeneous variance was investigated. In several studies, we observed the significant evidence of unequal error variances (Huang et al., 1992), while here there were not. Under this circumstance, weighted least-squares may not significantly improve model performance but may increase model fit slightly (Zhang, 1997). Therefore, ordinary nonlinear least-squares were used for parameter estimation instead than weighted least-squares. Every model was assessed using a coefficient of determination $\left(\mathrm{R}^{2}\right)$ and root mean square error (RMSE).

Table 3. Height-diameter functions selected for evaluation

\begin{tabular}{c|c}
\hline Function number and form & References \\
\hline (1) $H=1.3+\frac{D^{2}}{(a+b D)^{2}}$ & Loetsch et al. (1973) \\
\hline (2) $H=1.3+\frac{a}{\left(1+D^{-1}\right)^{b}}$ & Curtis (1967) \\
\hline (3) $H=1.3+a e^{-b /(D+c)}$ & Ratkowsky (1990) \\
\hline (4) $H=1.3+a\left(1-e^{-b D^{c}}\right)$ & Yang et al. (1978) \\
\hline (5) $H=1.3+a\left(1-e^{-b D}\right)^{c}$ & Richards (1959) \\
\hline
\end{tabular}




\begin{tabular}{|c|c|}
\hline (6) $H=1.3+e^{\left(a+\frac{b}{D+1}\right)}$ & Wykoff et al.(1982) \\
\hline (7) $H=1.3+a D^{b D^{-c}}$ & Sibbesen (1981) \\
\hline (8) $H=1.3+a e^{-b D^{-c}}$ & Zeide (1989) \\
\hline (9) $H=1.3+a e^{-b \mathrm{e}^{-\mathrm{CD}}}$ & Winsor (1932) \\
\hline (10) $H=a e^{-\exp (-b(D-c))}$ & Seber and Wild (1989) \\
\hline (11) $H=a\left(1-\exp \left\{-b D^{c}\right\}\right)$ & Bailey (1979) \\
\hline (12) $H=1.3+a e^{b / D}$ & Loetsch et al. (1973) \\
\hline (13) $H=1.3+10^{a} D^{b}$ & Burkhart and Strub (1974); Buford (1986); Larson (1986); Watts (1983) \\
\hline (14) $H=1.3+a D /(b+D)$ & Bates and Watts (1980); Ratkowsky (1990) \\
\hline (15) $H=1.3+a\left(1-e^{-b D}\right)$ & Bates and Watts (1980); Ratkowsky (1990) \\
\hline (16) $H=1.3+\frac{a D}{(D+1)}+b D$ & Watts (1983) \\
\hline (17) $H=1.3+a /\left(1+b e^{-c D}\right.$ & Paerl and Reed (1920) \\
\hline (18) $H=a\left(1-b \exp \left\{-c D^{d}\right\}\right)$ & Bailey (1979), Seber and Wild (1989) \\
\hline (19) $H=1.3+D^{2} /\left(a+b D+c D^{2}\right)$ & Curtis (1967); Prodan (1968) \\
\hline (20) $H=1.3+a e^{b /(D+c)}$ & Ratkowsky (1990) \\
\hline (21) $H=1.3+a /\left(1+b^{-1} D^{-c}\right.$ & Ratkowsky and Reedy (1986) \\
\hline (22) $H=e^{a+b /(D+1)}$ & Wykoff et al. (1982), Huang and Titus (1992) \\
\hline (23) $H=a D /(b+D)$ & Tang (1994), Bates and Watts (1980), Ratkowsky and Reedy (1986) \\
\hline (24) $H=a \exp \left\{-b \exp \left[-c D^{d}\right]\right\}$ & Zeide (1993) \\
\hline (25) $H=a+b D+c D^{2}$ & Henricksen (1950), Curtis (1967) \\
\hline (26) $H=1.3+a D^{b}$ & Stoffels and van Soest (1953); Stage, 1975 \\
\hline (27) $H=a /\left(1+e^{-b(D-c)}\right.$ & Seber and Wild (1989) \\
\hline (28) $H=a+b /(D+c)$ & Tang (1994) \\
\hline (29) $H=a e^{b /(D+c)}$ & Ratkowsky (1990), Huang and Titus (1992) \\
\hline (30) $H=a\left(1-e^{-b D}\right)$ & Meyer (1940), Farr et al. (1989), Moffat et al. (1991) \\
\hline
\end{tabular}

$\mathrm{H}=$ total height $(\mathrm{m}) ; \mathrm{D}=$ diameter at breast height outside bark $(\mathrm{cm}) ; \mathrm{a}, \mathrm{b}, \mathrm{c}, \mathrm{d}=$ parameters to be estimated; $\mathrm{e}=$ base of the natural $\operatorname{logarithm}(\approx 2.71828) ; 1.3=$ a constant commonly used to avoid the prediction of a height less than 1.3 meters when $\mathrm{D}$ is small

Through comparisons, the Chapman-Richards function was considered one of the best nonlinear functions for describing the relationship between height and diameter of the Dahurian larch and selected as the base model. The function on Chapman-Richards as represented by the following equation: 


$$
H=1.3+a\left[1-e^{-b . D}\right]^{c}
$$

where: H: total tree height $(\mathrm{m})$; D: tree diameter at breast height $(\mathrm{cm})$; a: the asymptotic parameter; b: the rate parameter; c: the shape parameter.

The Chapman-Richards function was fit to: (1) the overall data $(\mathrm{N}=2411)$; (2) the NWYLHLM region data (915); (3) the SAYLHLM region data (758); (4) the NDXAM region data (738); (5) each of ten subregions separately. Parameter estimates and evaluation statistics were calculated using SAS PROC NLIN procedure (SAS Institute, Inc., 1999) for overall model, three regional models, and ten subregional models. The non-linear extra sum of squares method was used (Bates and Watts, 1988) to assimilate the difference of the height-diameter relationships among different subregions. The nonlinear extra sum of squares method demands the fitting of full and reduced models and has commonly been applied to evaluate if separate models needed for different species or different geographic regions (Huang, 2000; Peng, 2001; Zhang, 2002; Corral-Rivas et al., 2004, 2007; Castedo-Dorado et al., 2005). The full model varieties to different sets of parameters for each subregion and is gotten by enlarging each parameter by including an associated parameter and a dummy variable to distinguish among subregions. The reduced model corresponds to the same set of global parameters for all subregions. Using Indicator (dummy) variable approach, the full model of the Chapman-Richards function can be written as:

$$
H=1.3+\left(a+\sum_{i=1}^{k} a_{i} z_{i}\right)\left[1-e^{-\left(b+\sum_{i=1}^{k} b_{i} z_{i}\right) \cdot D B H}\right]^{\left(c+\sum_{i=1}^{k} c_{i} z_{i}\right)}
$$

(1) To evaluate the overall differences among regions. Two indicator variables $(\mathrm{k}=2)$ are needed in Equation 2 for three regions. They are set as follows:

If region $=$ NWYLHLM, $\mathrm{z}_{1}=1, \mathrm{z}_{2}=0$;

If region $=\mathrm{SAYLHLM}, \mathrm{z}_{1}=0, \mathrm{z}_{2}=1$

If region $=\mathrm{NDXAM}, \mathrm{z}_{1}=0, \mathrm{z}_{2}=0$.

(2) To evaluate the differences between the three regions. A total of 3 region pairs can be formulated to test the pairwise differences between the three regions. The 3 testing pairs require 3 full models that take the form of Equation 2, and 3 reduced models that take the form of Equation 1. For example, to test the difference between region NWYLHLM vs. SAYLHLM, one indicator variable $(\mathrm{k}=1)$ can be defined: if region $=$ NWYLHLM, $Z_{1}=1$; and if region $=S A Y L H L M Z_{1}=0$. Similarly, the full model (Eq. 2) has 6 estimable parameters.

(3) To evaluate the overall differences among subregions. Nine indicator variables $(\mathrm{k}=9)$ are needed in Equation 2 for ten subregions. They are defined as follows:

If subregion $=\mathrm{SL}, \mathrm{z}_{1}=1$, all other $\mathrm{z}_{\mathrm{i}}=0$;

If subregion $=\mathrm{JGDQ}, \mathrm{z}_{2}=1$, all other $\mathrm{z}_{\mathrm{i}}=0$;

If subregion $=\mathrm{XL}, \mathrm{z}_{3}=1$, all other $\mathrm{z}_{\mathrm{i}}=0$;

If subregion $=\mathrm{TH}, \mathrm{z}_{4}=1$, all other $\mathrm{z}_{\mathrm{i}}=0$;

If subregion $=\mathrm{HZ}, \mathrm{z}_{5}=1$, all other $\mathrm{Z}_{\mathrm{i}}=0$;

If subregion $=S B Z, z_{6}=1$, all other $Z_{i}=0$;

If subregion $=\mathrm{HJY}, \mathrm{z}_{7}=1$, all other $\mathrm{Z}_{\mathrm{i}}=0$;

If subregion $=\mathrm{XLJ}, \mathrm{z}_{8}=1$, all other $\mathrm{z}_{\mathrm{i}}=0$;

If subregion $=\mathrm{TQ}, \mathrm{z}_{9}=1$, all other $\mathrm{z}_{\mathrm{i}}=0$; 
If subregion $=\mathrm{AME}$, all other $\mathrm{z}_{\mathrm{i}}=0$.

(4) To evaluate the differences between the ten subregions: A total of 45 subregion pairs can be formulated to test the pairwise differences between the ten subregions. The 45 testing pairs require 45 full models that take the form of Equation 2, and 45 reduced models that take the form of Equation 1. For example, to test the difference between subregion SL vs XL, one indicator variable $(\mathrm{k}=1)$ can be defined: if subregion $=\mathrm{SL}$, $\mathrm{Z}_{1}=1$; and if subregion $=\mathrm{XL}, \mathrm{Z}_{1}=0$. Similarly, the full model $(E q .2)$ has 6 estimable parameters. All the reduced models for these tests take the form of Equation 1 with 3 parameters. The nonlinear extra sum of squares for comparing the full and reduced models follows an F-distribution and uses the following expression:

$$
F=\frac{\left(S S E_{R}-S S E_{F}\right) /\left(d f_{R-} d f_{F}\right)}{\left(S S E_{F}\right) /\left(d f_{F}\right)}
$$

where $S S E_{R}$ and $d_{R}$ are the error sum of squares and degrees of freedom related with the reduced model and $\mathrm{SSE}_{\mathrm{F}}$ and $\mathrm{df}_{\mathrm{F}}$ are error sum of squares and degrees of freedom related with a full model. Generally, the F-test is meaningful if the p-value for the test is least than 0.05 .

To evaluate the performances of applying a height-diameter model to different subregion; each of the fourteen models (overall model, three regional models, and ten subregional models) was used to predict total tree heights for each subregion. Using the observed and predicted total tree heights, the following criteria were used to assess the predictive capability and significant test (Zhang et al., 2002; Cutini et al., 2013; Peng et al., 2004):

$$
\begin{gathered}
\bar{e}=\frac{\sum_{i=1}^{m}\left(H_{i}-\hat{H}_{i}\right)}{m} \\
S_{e}=\sqrt{\frac{\sum_{i=1}^{m}\left(e_{i}-\bar{e}_{i}\right)^{2}}{m-1}} \\
\bar{e} \%=\frac{\sigma}{B} X 100 \\
t=\frac{\overline{\mathrm{e}}}{S_{E / \sqrt{m}}}
\end{gathered}
$$

where $e_{i}$ is the unlike between the observed $(H i)$ and predicted $(\hat{H i})$ height for the $i$ the observation $(\mathrm{i}=1,2, \ldots, \mathrm{m})$ with $m$ being the number of observations in the concerned subregion, $\overline{\mathrm{e}}$ is mean prediction error; $S e$ is the standard deviation of the prediction error; $\overline{\mathrm{e}} \%$ is percent prediction error, $\bar{H}$ is the mean of observed heights; $t$ is a t-test used to test the null hypothesis that the mean prediction error equals zero. Although overall evaluation ( $\overline{\mathrm{e}}, \overline{\mathrm{e}} \%$ and $\mathrm{t}$-test) are good indicators of the consequences of inappropriately applying a height-diameter model in different subregions, they may not be indicated the quality of prediction for different diameter classes in each of the ten subregions. Therefore, the height-diameter models (Overall model, three regional models, and ten subregional models) were further assessed by use of plots of prediction errors against diameter classes (5-cm diameter intervals) in each of the ten subregions. 


\section{Results and discussion}

\section{Selection of the height-diameter model}

Parameter estimates and fitting statistics for the candidate models are listed in Table 4.

The t-statistics for the parameters of these functions were all significant at the significant level of 0.0001 . The coefficient of determination $\left(\mathrm{R}^{2}\right)$ of all functions was within the range from 0.7607 to 0.8221 , and the RMSE was within the range from 2.193 to $2.5347 \mathrm{~m}$. The Chapman-Richards function (model 5) had the smallest RMSE value and highest $\mathrm{R}^{2}$ value.

Table 4. Comparison of height-diameter on the Dahurian larch model fitting data set

\begin{tabular}{|c|c|c|c|c|c|c|c|}
\hline \multirow{2}{*}{ Function } & \multicolumn{4}{|c|}{ Estimated coefficients } & \multirow{2}{*}{$\mathbf{n}$} & \multirow{2}{*}{ RMSE } & \multirow{2}{*}{$\mathbf{R}^{2}$} \\
\hline & $\mathbf{a}$ & b & c & d & & & \\
\hline (1) & 0.6543 & 0.0304 & - & - & 2411 & 2.2024 & 0.8194 \\
\hline (2) & 27.2134 & 10.2849 & - & - & 2411 & 2.2642 & 0.8091 \\
\hline (3) & 32.5708 & 16.7877 & 6.3255 & - & 2411 & 2.2044 & 0.8191 \\
\hline (4) & 25.9089 & 0.049 & 0.0593 & - & 2411 & 2.206 & 0.8205 \\
\hline (5) & 25.9018 & 0.0392 & 0.8114 & - & 2411 & 2.193 & 0.8221 \\
\hline (6) & 2.3244 & -8.7643 & - & - & 2411 & 2.3006 & 0.8029 \\
\hline (7) & 3.5664 & 1.5361 & 1.05 & - & 2411 & 2.287 & 0.8052 \\
\hline (8) & 43.2886 & 4.5309 & 0.5037 & - & 2411 & 2.198 & 0.8217 \\
\hline (9) & 23.7396 & 1.7099 & 0.0712 & - & 2411 & 2.2414 & 0.813 \\
\hline (10) & 2.887 & 0.3362 & 19 & - & 2411 & 2.5347 & 0.7607 \\
\hline (11) & 117.0832 & 0.0345 & 0.4507 & - & 2411 & 2.2738 & 0.8074 \\
\hline (12) & 26.8223 & -9.6581 & - & - & 2411 & 2.2814 & 0.8061 \\
\hline (13) & 0.5519 & 0.4863 & - & - & 2411 & 2.287 & 0.8052 \\
\hline (14) & 32.8961 & 21.5312 & - & - & 2411 & 2.2024 & 0.8194 \\
\hline (15) & 24.1895 & 0.0541 & - & - & 2411 & 2.2223 & 0.8161 \\
\hline (16) & 9.025 & 0.3143 & - & - & 2411 & 2.4634 & 0.7739 \\
\hline (17) & 23.0775 & 3.2223 & 0.0955 & - & 2411 & 2.2715 & 0.8079 \\
\hline (18) & 77.0078 & 0.1805 & -1.8397 & -0.0792 & 2411 & 2.2205 & 0.7749 \\
\hline (19) & -0.216 & -0.9696 & 0.8704 & - & 2411 & 2.2024 & 0.8194 \\
\hline (20) & 31.1265 & -17.1302 & 5.5443 & - & 2411 & 2.2049 & 0.8189 \\
\hline (21) & 32.8964 & 0.0464 & - & - & 2411 & 2.2024 & 0.8194 \\
\hline (22) & 2.32433 & -8.7608 & - & - & 2411 & 2.3006 & 0.8029 \\
\hline (23) & 25.0865 & 0.9393 & 0.0467 & - & 2411 & 2.2141 & 0.8175 \\
\hline (24) & 97.2516 & 0.428 & -2.4736 & -0.1904 & 2411 & 2.2091 & 0.8203 \\
\hline (25) & 32.1933 & 0.0451 & 1.0246 & - & 2411 & 2.2027 & 0.8194 \\
\hline (26) & 3.56433 & 0.4863 & - & - & 2411 & 2.2872 & 0.8052 \\
\hline (27) & 24.4738 & 0.0916 & -1.0217 & - & 2411 & 2.2647 & 0.8091 \\
\hline (28) & 34.8772 & 17.1059 & 0.9376 & - & 2411 & 2.2009 & 0.8197 \\
\hline (29) & 32.563 & -16.7739 & 6.3157 & - & 2411 & 2.2044 & 0.8191 \\
\hline (30) & 24.9065 & 0.0603 & - & - & 2411 & 2.2416 & 0.8129 \\
\hline
\end{tabular}

Functions are shown in Table 2. The higher $\mathrm{R}^{2}$ values are found in functions 5, 8 and 4, respectively 


\section{Fitting the Chapman-Richards model to regional and subregional data}

Based on the Chapman-Richards function, Table 5 shows the sample sizes, parameter estimates, and mean square errors (MSE) for all the fourteen fitted models (overall model, three regional models, and ten subregional models). The four regional models (Overall, NWYLHLM, SAYLHLM, and NDXAM) have different model MSEs and parameter estimates. Among the ten subregional models, the lowest MSE value was found in the XLJ subregion (MSE = 2.1909), while the highest MSE value was found in the JGDQ subregion (MSE = 4.5703). The asymptote parameter ( $\mathrm{a}$ in Table 5) ranged from 19.9264 to 32.8497, rate parameter (b in Table 5) ranged from 0.0197 to 0.1225 , and shape parameter (c in Table 5) ranged from 0.6323 to 1.559 . The parameter estimates varied among the ten subregions, indicating that each subregion may have a different height-diameter relationship with others.

Table 5. Parameter estimations and model MSE of Chapman-Richards function for the regional and subregional models

\begin{tabular}{c|c|c|c|c|c}
\hline Subregion & $\mathbf{N}$ & $\mathbf{a}$ & $\mathbf{b}$ & $\mathbf{c}$ & MSE \\
\hline SL & 214 & 32.8497 & 0.0197 & 0.6323 & 2.9089 \\
JGDQ & 524 & 23.7489 & 0.052 & 0.9244 & 4.5703 \\
XL & 190 & 22.8785 & 0.0591 & 1.0135 & 3.2597 \\
TH & 203 & 23.2172 & 0.0583 & 1.2253 & 3.5829 \\
HZ & 215 & 19.9264 & 0.093 & 1.559 & 3.7469 \\
SBZ & 237 & 21.9893 & 0.0662 & 1.0635 & 3.3236 \\
HJY & 128 & 21.6856 & 0.0761 & 1.3459 & 3.5877 \\
XLJ & 224 & 20.3106 & 0.1225 & 1.4833 & 2.1909 \\
TQ & 191 & 23.8895 & 0.0539 & 0.8703 & 2.9696 \\
AME & 285 & 29.5955 & 0.0358 & 0.8211 & 3.5748 \\
NWYLHLM & 915 & 23.1747 & 0.0561 & 0.8434 & 5.0139 \\
SAYLHLM & 758 & 20.6695 & 0.0942 & 1.3421 & 4.9493 \\
NDXAM & 738 & 26.6823 & 0.0318 & 0.6735 & 3.9431 \\
Overall & 2411 & 25.4937 & 0.0421 & 0.8381 & 4.7716 \\
\hline
\end{tabular}

$\mathrm{N}$ : sample size (number of trees); $a, b, c$ : three parameters of Chapman-Richards function; MSE: model mean squared error

\section{Comparison of height-diameter models among subregions and between regions}

The fitting results of the reduced and full height-diameter models on combination data are provided in Table 6 (first row). The F-test result reveals that there are overall significant differences $(\mathrm{P}<0.05)$ among subregions. Since the divergences may be caused by as few as two or as many as all of the subregions implicated, indicator variable approach was also carried out for every eventual pair of subregions then, the source of the differences could be identified and data from similar subregion can be combined. Same analyses were realized for others subregions pairs and F-values were calculated (Table 6). 

mountains in China

$$
-13576 \text { - }
$$

Table 6. F-test for testing the differences between subregions

\begin{tabular}{|c|c|c|c|c|c|c|c|c|c|c|}
\hline \multirow{2}{*}{$\begin{array}{l}\text { Subregion } \\
\text { pairs }\end{array}$} & \multirow{2}{*}{$\mathbf{n}$} & \multicolumn{3}{|c|}{ Full model } & \multicolumn{3}{|c|}{ Reduced model } & \multicolumn{3}{|c|}{ Extra sum of squares } \\
\hline & & SSEF $_{F}$ & $P F$ & $\mathrm{~d} f \mathbf{F}$ & $\mathrm{SSE}_{\mathrm{R}}$ & $P \mathrm{R}$ & $\mathrm{d} f \mathbf{R}$ & d $f$ R-d $f F$ & F-value & Prob $>F$ \\
\hline Combined & 2411 & 8384.62 & 30 & 2381 & 11489.91 & 3 & 2408 & 27 & 32.6599 & $<0.0001$ \\
\hline SL-JGDQ & 738 & 2987.39 & 6 & 732 & 3197.37 & 3 & 735 & 3 & 17.1503 & $<0.0001$ \\
\hline SL-XL & 404 & 1215.82 & 6 & 398 & 1432.11 & 3 & 401 & 3 & 23.5886 & $<0.0001$ \\
\hline SL-TH & 417 & 1322.84 & 6 & 411 & 1644.46 & 3 & 414 & 3 & 33.3093 & $<0.0001$ \\
\hline SL-HZ & 429 & 1400.62 & 6 & 423 & 1897.39 & 3 & 426 & 3 & 50.0105 & $<0.0001$ \\
\hline SL-SBZ & 451 & 1383.98 & 6 & 445 & 1688.71 & 3 & 448 & 3 & 32.6613 & $<0.0001$ \\
\hline SL-HJY & 342 & 1054.72 & 6 & 336 & 1273.91 & 3 & 339 & 3 & 3.2741 & $<0.0001$ \\
\hline SL-XLJ & 438 & 1090.46 & 6 & 432 & 1344.92 & 3 & 435 & 3 & 33.6032 & $<0.0001$ \\
\hline SL-TQ & 405 & 1164.55 & 6 & 399 & 1259.24 & 3 & 402 & 3 & 10.8145 & $<0.0001$ \\
\hline SLAME & 499 & 1614.37 & 6 & 493 & 1767.71 & 3 & 496 & 3 & 5.6082 & $<0.0001$ \\
\hline JGDQ-XL & 714 & 2990.69 & 6 & 708 & 2998.95 & 3 & 711 & 3 & 65198 & 0.5818 \\
\hline JGDQ-TH & 727 & 3097.71 & 6 & 721 & 3309.85 & 3 & 724 & 3 & 596 & $<0.0001$ \\
\hline JGDQ-HZ & 739 & 3175.48 & 6 & 733 & 3412.48 & 0 & 736 & 3 & .2358 & $<0.0001$ \\
\hline JGDQ-SBZ & 761 & 3158 & 6 & 755 & 3194.41 & 8 & 758 & 3 & 2.8332 & 0.0374 \\
\hline JGDQ-HJY & 652 & 2829.59 & 6 & 646 & 2876.78 & 2 & 649 & 3 & 3.5915 & 0.0135 \\
\hline JGDQ-XLJ & 748 & 2865.32 & 6 & 742 & 3211.65 & 2 & 745 & 3 & 29.8955 & $<0.0001$ \\
\hline JGDQ-TQ & 715 & 2939.41 & 6 & 709 & 3001.53 & 2 & 712 & 3 & 4.9941 & 0.001 \\
\hline JGDQ-AME & 809 & 3389.23 & 6 & 803 & 4268.31 & 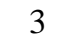 & 806 & 3 & 69.4259 & $<0.0001$ \\
\hline XL-TH & 393 & 1326.13 & 6 & 387 & 1403.78 & 3 & 390 & 3 & 7.5532 & $<0.0001$ \\
\hline XL-HZ & 405 & 1403.91 & 6 & 399 & 1518.73 & 3 & 402 & 3 & 10.8774 & $<0.0001$ \\
\hline XL-SBZ & 427 & 1387.27 & 6 & 421 & 1394.93 & 3 & 424 & 3 & 0.7754 & 0.5081 \\
\hline XL-HJY & 318 & 1058.01 & 6 & 312 & 1073.08 & 3 & 315 & 3 & 1.4806 & 0.2197 \\
\hline XL-XLJ & 414 & 1093.75 & 6 & 408 & 1295.78 & 3 & 411 & 3 & 25.1214 & $<0.0001$ \\
\hline XL-TQ & 381 & 1167.84 & 6 & 375 & 1228.81 & 3 & 378 & 3 & 6.5251 & $<0.0001$ \\
\hline XL-AME & 475 & 1617.66 & 6 & 469 & 2329.86 & 3 & 472 & 3 & 68.8285 & $<0.0001$ \\
\hline TH-HZ & 418 & 1513.73 & 6 & 412 & 1575.63 & 3 & 415 & 3 & 5.6159 & 0.0008 \\
\hline TH-SBZ & 440 & 1494.29 & 6 & 434 & 1614.13 & 3 & 437 & 3 & 11.6025 & $<0.0001$ \\
\hline TH-HJY & 331 & 1165.03 & 6 & 325 & 1197.56 & 3 & 328 & 3 & 3.0253 & 0.0297 \\
\hline TH-XLJ & 427 & 1200.76 & 6 & 421 & 2044.52 & 3 & 424 & 3 & 98.6095 & $<0.0001$ \\
\hline TH-TQ & 394 & 1274.86 & 6 & 388 & 1645.46 & 3 & 391 & 3 & 37.5979 & $<0.0001$ \\
\hline TH-AME & 488 & 1724.67 & 6 & 482 & 2476.83 & 3 & 485 & 3 & 70.0693 & $<0.0001$ \\
\hline HZ-SBZ & 452 & 1572.06 & 6 & 446 & 1669.39 & 3 & 449 & 3 & 9.2041 & $<0.0001$ \\
\hline HZ-HJY & 343 & 1242.81 & 6 & 337 & 1281.43 & 3 & 340 & 3 & 3.4912 & 0.016 \\
\hline HZ-XLJ & 439 & 1278.54 & 6 & 433 & 1855.69 & 3 & 436 & 3 & 65.1539 & $<0.0001$ \\
\hline HZ-TQ & 406 & 1352.63 & 6 & 400 & 1717.23 & 3 & 403 & 3 & 35.9388 & $<0.0001$ \\
\hline HZ-AME & 500 & 1802.45 & 6 & 494 & 2905.22 & 3 & 497 & 3 & 100.746 & $<0.0001$ \\
\hline SBZ-HJY & 365 & 1226.17 & 6 & 359 & 1241.61 & 3 & 362 & 3 & 1.5059 & 0.2126 \\
\hline SBZ-XLJ & 461 & 1261.91 & 6 & 455 & 1511.42 & 3 & 458 & 3 & 29.9889 & $<0.0001$ \\
\hline SBZ-TQ & 428 & 1336.11 & 6 & 422 & 1441.02 & 3 & 425 & 3 & 11.0583 & $<0.0001$ \\
\hline SBZ-AME & 522 & 1785.81 & 6 & 516 & 2670.94 & 3 & 519 & 3 & 85.2504 & $<0.0001$ \\
\hline HJY-XLJ & 352 & 932.648 & 6 & 346 & 1217.74 & 3 & 349 & 3 & 35.2549 & $<0.0001$ \\
\hline HJY-TQ & 319 & 1006.74 & 6 & 313 & 1138.21 & 3 & 316 & 3 & 13.6241 & $<0.0001$ \\
\hline HJY-AME & 413 & 1456.56 & 6 & 407 & 2042.31 & 3 & 410 & 3 & 54.5582 & $<0.0001$ \\
\hline XLJ-TQ & 415 & 1042.47 & 6 & 409 & 1135.14 & 3 & 412 & 3 & 12.1191 & $<0.0001$ \\
\hline XLJ-AME & 50 & 1492.29 & 6 & 503 & 1691.66 & 3 & 506 & 3 & 22.3999 & $<0.0001$ \\
\hline TQ-AME & 476 & 1566.39 & 6 & 470 & 1858.71 & 3 & 473 & 3 & 29.2372 & $<0.0001$ \\
\hline
\end{tabular}

The F-values were calculated according to Equation 3. The number of observations is represented by $n$; $p$ is the number of parameters; $\mathrm{SSE}_{\mathrm{F}}, \mathrm{d} f \mathrm{~F}, \mathrm{SSE}_{\mathrm{R}}$ and $\mathrm{d} f \mathrm{R}$ are the sum of squared errors and the degrees of freedom associated with the full and reduced models, respectively 
Among the 45 pairs of subregions, only four subregion pairs (e.g., XL versus SBZ, XL versus HJY, SBZ versus HJY, and XL versus JGDQ) showed the non-significant difference $F$-value $(\mathrm{P}>0.05)$. Therefore, the data from these three subregions (XL, SBZ, and HJY) were then combined, and seven new subregion pairs were formed as follows:

Subregion $(\mathrm{XL}+\mathrm{SBZ}+\mathrm{HJY})$ and SL;

Subregion (XL + SBZ + HJY) and JGDQ;

Subregion $(\mathrm{XL}+\mathrm{SBZ}+\mathrm{HJY})$ and $\mathrm{TH}$;

Subregion (XL + SBZ + HJY) and HZ;

Subregion (XL + SBZ + HJY) and XLJ;

Subregion $(\mathrm{XL}+\mathrm{SBZ}+\mathrm{HJY})$ and TQ;

Subregion $(\mathrm{XL}+\mathrm{SBZ}+\mathrm{HJY})$ and AME

Subsequent F-tests show that the height-diameter relationship for the combined subregions $(\mathrm{XL}+\mathrm{SBZ}+\mathrm{HJY})$ is different from those for SL, JGDQ, TH, HZ, XLJ, TQ and AME $(\mathrm{P}<0.05$, Table 7$)$.

Table 7. F-test for testing the differences between combined subregions $(X L+S B Z+H J Y)$ with each subregion

\begin{tabular}{c|c|c|c|c|c|c|c|c|c|c}
\hline \multirow{2}{*}{ Subregion pairs } & \multirow{2}{*}{$\mathbf{n}$} & \multicolumn{3}{|c|}{ Full model } & \multicolumn{3}{c|}{ Reduced model } & \multicolumn{3}{c}{ Extra sum of squares } \\
\cline { 3 - 10 } & & SSEF $_{\mathbf{F}}$ & $\boldsymbol{P F}$ & $\mathbf{d} f \mathbf{F}$ & SSE $_{\mathbf{R}}$ & $\boldsymbol{P R}$ & $\mathbf{d} f \mathbf{R}$ & $\mathbf{d} \boldsymbol{f} \mathbf{R}-\mathbf{d} f \mathbf{F}$ & F-value & Prob $>\boldsymbol{F}$ \\
\hline (XL + SBZ + HJY) - SL & 766 & 2467.85 & 6 & 763 & 2870.74 & 3 & 766 & 3 & 41.5217 & $<0.0001$ \\
(XL + SBZ + HJY) - JGDQ & 1076 & 4242.71 & 6 & 1073 & 4288.13 & 3 & 1076 & 3 & 3.8286 & 0.0096 \\
(XL + SBZ + HJY) - TH & 755 & 2578.16 & 6 & 752 & 2708.07 & 3 & 755 & 3 & 12.6308 & $<0.0001$ \\
(XL + SBZ + HJY) - HZ & 767 & 2655.93 & 6 & 764 & 2778.32 & 3 & 767 & 3 & 11.7353 & $<0.0001$ \\
(XL + SBZ + HJY) - XLJ & 776 & 2345.77 & 6 & 773 & 2780.56 & 3 & 776 & 3 & 47.7581 & $<0.0001$ \\
(XL + SBZ + HJY) - TQ & 743 & 2419.87 & 6 & 740 & 2567.41 & 3 & 743 & 3 & 15.0381 & $<0.0001$ \\
(XL + SBZ + HJY) - AME & 837 & 2869.69 & 6 & 834 & 4205.94 & 3 & 837 & 3 & 129.4491 & $<0.0001$ \\
\hline
\end{tabular}

The F-values were calculated according to Equation 3. The number of observations is represented by $n ; p$ is the number of parameters; $\mathrm{SSE}_{\mathrm{F}}, \mathrm{d} f \mathrm{~F}, \mathrm{SSE}_{\mathrm{R}}$ and $\mathrm{d} f \mathrm{R}$ are the sum of squared errors and the degrees of freedom associated with the full and reduced models, respectively

Based on regional classification in Table 2, Dahurian larch has three regions with three pairs (NWYLHLM, SAYLHLM, and NDXAM), the three pairs require the fittings of the 6 nonlinear regression models to give error sums of squares, so that the Ftest can be carried out for each pair. The F-test also indicates that there are over significant differences $(\mathrm{P}<0.05)$ among regions (Table 8, first row). All of the three regional paired comparisons produced significant $\mathrm{F}$ values, suggesting that significant different height-diameter equations are required.

Table 8. F-test for testing the differences between regions

\begin{tabular}{c|c|c|c|c|c|c|c|c|c|c}
\hline \multirow{2}{*}{ Region pairs } & \multirow{2}{*}{$\mathbf{n}$} & \multicolumn{3}{|c|}{ Full model } & \multicolumn{3}{c|}{ Reduced model } & \multicolumn{3}{c}{ Extra sum of squares } \\
\cline { 3 - 11 } & & SSE $_{\mathbf{F}}$ & $\boldsymbol{P F}$ & $\mathbf{d} f \mathbf{F}$ & SSE & $\boldsymbol{P R}$ & $\mathbf{d} f \mathbf{R}$ & $\mathbf{d} f \mathbf{R}-\mathbf{d} f \mathbf{F}$ & F-value & Prob $>\boldsymbol{F}$ \\
\hline Combined & 2411 & 10425.81 & 9 & 2402 & 11489.91 & 3 & 2408 & 6 & 40.8582 & $<0.0001$ \\
NWYLHLM-SAYLHLM & 1673 & 7228.47 & 6 & 1667 & 8286.89 & 3 & 1670 & 3 & 81.3629 & $<0.0001$ \\
NWYLHLM-NDXAM & 1653 & 7717.78 & 6 & 1647 & 7925.83 & 3 & 1650 & 3 & 14.7998 & $<0.0001$ \\
SAYLHLM-NDXAM & 1496 & 5905.44 & 6 & 1490 & 6218.61 & 3 & 1493 & 3 & 26.3381 & $<0.0001$ \\
\hline
\end{tabular}

The F-values were calculated according to Equation 3. The number of observations is represented by $n ; p$ is the number of parameters; $\mathrm{SSE}_{\mathrm{F}}, \mathrm{d} f \mathrm{~F}, \mathrm{SSE}_{\mathrm{R}}$ and $\mathrm{d} f \mathrm{R}$ are the sum of squared errors and the degrees of freedom associated with the full and reduced models, respectively 


$$
-13578 \text { - }
$$

\section{Prediction errors of applying regional and overall models to each subregion}

According to the above F-tests, there were significant differences for most subregion pairs in the height-diameter relationships. It has been shown that there are statistically significant differences between the tested subregions, but that does not imply that these differences have practical importance. In practice, incorrectly applying a heightdiameter model in these subregions may result in prediction biases. To understand the consequences, all 14 models (overall model, NWYLHLM model, SAYLHLM model, NDXAM model, and ten subregional models) were used to predict total tree heights for a given subregion individually. The mean prediction error $(\overline{\mathrm{e}})$, the percent prediction error $(\overline{\mathrm{e}} \%)$, and the t-test for testing the null hypothesis that means prediction error equals zero were shown in Tables 9 and 10.

Table 9. Prediction error of applying the overall model to each subregion

\begin{tabular}{c|c|c|c|c|c|c|c|c}
\hline Subregion & $\mathbf{N}$ & $\overline{\mathbf{H}}(\mathbf{m})$ & $\hat{\mathbf{H}}(\mathbf{m})$ & $\overline{\mathbf{e}}$ & $\mathbf{\mathbf { e }} \%$ & $\mathbf{S e}$ & $\mathbf{t}$ & $\mathbf{p}$-value \\
\hline SL & 214 & 19.58 & 18.99 & 0.58 & 2.99 & 1.79 & 4.79 & $<0.0001$ \\
JGDQ & 524 & 18.29 & 18.55 & -0.26 & -1.42 & 2.14 & -2.77 & 0.005 \\
XL & 240 & 18.7 & 19.54 & -0.83 & -4.48 & 2.08 & -6.24 & $<0.0001$ \\
TH & 203 & 15.34 & 16.69 & -1.35 & -8.83 & 1.92 & -10.01 & $<0.0001$ \\
HZ & 215 & 16.12 & 17.44 & -1.31 & -8.18 & 2.02 & -9.56 & $<0.0001$ \\
SBZ & 237 & 17.93 & 18.56 & -0.63 & -3.51 & 1.88 & -5.13 & $<0.0001$ \\
HJY & 128 & 17.7 & 18.55 & -0.83 & -4.69 & 1.93 & -4.87 & $<0.0001$ \\
XLJ & 224 & 15.75 & 14.42 & 1.33 & 8.45 & 1.66 & 11.98 & $<0.0001$ \\
TQ & 191 & 17.44 & 17.02 & 0.41 & 2.41 & 1.75 & 3.29 & 0.001 \\
AME & 285 & 22.36 & 20.52 & 1.84 & 8.24 & 1.99 & 15.64 & $<0.0001$ \\
\hline
\end{tabular}

$\mathrm{N}$ - sample size, $\overline{\mathrm{H}}-$ average of observed tree height, $\hat{\mathrm{H}}$ - average of predicted tree height from the overall model, $\overline{\mathbf{e}}$ - average of prediction error, $\overline{\mathrm{e}} \%$ - percent prediction error, $\mathrm{Se}$ - standard deviation of prediction error

The overall model was used to predict trees heights in each subregion, over or under predictions occurred for different subregions. The $\mathrm{p}$-value of the t-test was less than 0.05 for each of the ten subregions. On average, the overall model under-estimate (i.e., positive prediction error \%) trees heights from $2.4 \%$ to $8.45 \%$ for subregions SL, XLJ, TQ and AME, and over-estimate (i.e., negative prediction error \%) tree heights from $1.42 \%$ to $-8.83 \%$ for subregions JGDQ, XL, TH, HZ, SBZ and HJY (Table 9). Table 10 shows that when applying NWYLHLM model in each subregion, there is no difference between NWYLHLM-SL; NWYLHLM-TQ, while there is a difference in the others regions and subregions.

The same applies to SAYLHLM model, when the model is applied in each subregion, there is no difference between SAYLHLM-(subregions SBZ and HJY); there is a difference between others regions and subregions. When NDXAM model is applied in each subregion, there is no difference between NDXAM-(subregions JGDQ, $\mathrm{XL}$, and TQ), although there is a difference between others regions and subregion. The prediction biases ranged from -11.97 to $8.46 \%$ in NWYLHLM model; from -3.52 to $13.82 \%$ in SAYLHLM model; from -8.69 to $8.58 \%$ in NDXAM model. Then, applying 
regional height-diameters models in different subregions displays the variations bias in the predictions of heights that cannot help forest managers to predict the height of the model from other regions and make good decisions.

Table 10. Prediction errors of applying regional models to each subregion

\begin{tabular}{|c|c|c|c|c|c|c|c|c|}
\hline Region & $\mathbf{N}$ & $\overline{\mathbf{H}}_{(\mathbf{m})}$ & $\hat{\mathbf{H}}(\mathbf{m})$ & $\overline{\mathbf{e}}$ & $\overline{\mathrm{e}} \%$ & Se & $\mathbf{t}$ & p-value \\
\hline \multicolumn{9}{|l|}{ NWYLHLM model } \\
\hline NWYLHLM-SL & 214 & 19.58 & 19.74 & -0.16 & -0.75 & 1.70 & -1.4043 & 0.1616 \\
\hline NWYLHLM-JGDQ & 524 & 18.29 & 18.81 & -0.51 & -2.8 & 2.17 & -5.4094 & $<0.0001$ \\
\hline NWYLHLM-XL & 190 & 19.33 & 19.95 & -0.62 & -3.32 & 1.82 & -4.7005 & $<0.0001$ \\
\hline NWYLHLM-TH & 203 & 15.34 & 17.17 & -1.83 & -11.97 & 2.06 & -12.6611 & $<0.0001$ \\
\hline NWYLHLM-HZ & 215 & 16.12 & 17.87 & -1.74 & -10.83 & 1.96 & -13.0251 & $<0.0001$ \\
\hline NWYLHLM-SBZ & 237 & 17.93 & 18.79 & -0.85 & -4.79 & 1.82 & -7.2495 & $<0.0001$ \\
\hline NWYLHLM-HJY & 128 & 17.72 & 18.84 & -1.12 & -6.32 & 1.94 & -6.5253 & $<0.0001$ \\
\hline NWYLHLM-XLJ & 224 & 15.75 & 15.14 & 0.60 & 3.84 & 1.57 & 5.7623 & $<0.0001$ \\
\hline NWYLHLM-TQ & 191 & 17.44 & 17.38 & 0.06 & 0.36 & 1.73 & 0.511 & 0.6099 \\
\hline NWYLHLM-AME & 285 & 22.36 & 20.47 & 1.89 & 8.46 & 2.26 & 14.0901 & $<0.0001$ \\
\hline \multicolumn{9}{|l|}{ SAYLHLM model } \\
\hline SAYLHLM-SL & 214 & 19.58 & 18.10 & 1.48 & 7.55 & 1.91 & 11.3093 & $<0.0001$ \\
\hline SAYLHLM-JGDQ & 524 & 18.29 & 17.72 & 0.57 & 3.13 & 2.14 & 6.1232 & $<0.0001$ \\
\hline SAYLHLM-XL & 190 & 19.33 & 19.02 & 0.31 & 1.62 & 1.8 & 2.4013 & 0.0173 \\
\hline SAYLHLM-TH & 203 & 15.34 & 15.88 & -0.54 & -3.52 & 1.91 & -4.0206 & $<0.0001$ \\
\hline SAYLHLM-HZ & 215 & 16.12 & 16.67 & -0.54 & -3.38 & 1.97 & -4.0435 & $<0.0001$ \\
\hline SAYLHLM-SBZ & 237 & 17.93 & 17.71 & 0.21 & 1.22 & 1.85 & 1.8183 & 0.0702 \\
\hline SAYLHLM-HJY & 128 & 17.72 & 17.76 & -0.03 & -0.22 & 1.88 & -0.2369 & 0.8131 \\
\hline SAYLHLM-XLJ & 224 & 15.75 & 13.57 & 2.17 & 13.82 & 1.65 & 19.644 & $<0.0001$ \\
\hline SAYLHLM-TQ & 191 & 17.44 & 16.1 & 1.34 & 7.68 & 1.75 & 10.5944 & $<0.0001$ \\
\hline SAYLHLM-AME & 285 & 22.36 & 19.6 & 2.75 & 12.34 & 2.08 & 22.2962 & $<0.0001$ \\
\hline \multicolumn{9}{|l|}{ NDXAM model } \\
\hline NDXAM-SL & 214 & 19.58 & 18.99 & 0.58 & 2.99 & 1.77 & 4.8474 & $<0.0001$ \\
\hline NDXAM-JGDQ & 524 & 18.29 & 18.54 & -0.24 & -1.34 & 2.15 & -2.6219 & 0.0089 \\
\hline NDXAM-XL & 190 & 19.33 & 19.85 & -0.51 & -2.66 & 1.84 & -3.8427 & $<0.0001$ \\
\hline NDXAM-TH & 203 & 15.34 & 16.67 & -1.33 & -8.69 & 1.93 & -9.8154 & $<0.0001$ \\
\hline NDXAM-HZ & 215 & 16.12 & 17.41 & -1.29 & -8 & 2.03 & -9.2785 & $<0.0001$ \\
\hline NDXAM-SBZ & 237 & 17.93 & 18.55 & -0.62 & -3.45 & 1.9 & -5.0114 & $<0.0001$ \\
\hline NDXAM-HJY & 128 & 17.72 & 18.53 & -0.8 & -4.56 & 1.94 & -4.7005 & $<0.0001$ \\
\hline NDXAM-XLJ & 224 & 15.75 & 14.40 & 1.35 & 8.58 & 1.67 & 12.0851 & $<0.0001$ \\
\hline NDXAM-TQ & 191 & 17.44 & 17.03 & 0.41 & 2.38 & 1.76 & 3.2542 & 0.001 \\
\hline NDXAM-AME & 285 & 22.36 & 20.53 & 1.83 & 8.2 & 1.97 & 15.6945 & $<0.0001$ \\
\hline
\end{tabular}

$\mathrm{N}$ - sample size, $\overline{\mathrm{H}}$ - average of observed tree height, $\hat{\mathrm{H}}$ - average of predicted tree height from the model, $\overline{\mathbf{e}}-$ average of prediction error, $\overline{\mathrm{e}} \%$ - percent prediction error, $\mathrm{S}_{\mathrm{e}}-$ standard deviation of prediction error 
Figure 2 illustrates the average prediction errors across $5-\mathrm{cm} \mathrm{D}$ classes when NDXAM, NWYLHLM, SAYLHLM, Overall, and subregion models are applied to predict tree height in each of the ten subregions separately. Clearly, large negative values of the Overall model are observed in the $\mathrm{TH}$ and $\mathrm{HZ}$ subregions due an overestimation of large-sized trees. We also noticed negative values in the subregions JGDQ, XL, SBZ, and HJY. Large positive values of the Overall model are observed in the AME and XLJ subregions; it was also revealed that underestimations with positive values are observed in the SL and TQ subregions.

\section{Prediction errors of applying subregional model to each subregion}

Table Al (Appendix) shows that when the ten subregional models were applied to each subregion, they generally performed well only in the subregions in which the models were developed ( $\mathrm{p}$-value for $\mathrm{t}$-test $>0.05$ for testing that the mean prediction error equals zero). Otherwise, the models produced significant prediction errors. The prediction biases ranged from $-10.84 \%$ to $7.32 \%$ in SL; from $-7.64 \%$ to $9.87 \%$ in JGDQ; from $-5.89 \%$ to $11 \%$ in XL; from $-0.17 \%$ to $18.3 \% \mathrm{TH}$; from $-0.18 \%$ to $16.69 \%$ $\mathrm{HZ}$; from $-5.97 \%$ to $12.09 \%$ in SBZ; from $-3.32 \%$ to $12.85 \%$ HJY; from $-14.2 \%$ to $10.28 \%$ in XLJ; from $-12.22 \%$ to $7.35 \%$ in TQ; from $-17.02 \%$ to $2.44 \%$ in AME. The pvalues of the mean prediction biases were calculated using the paired t-test procedure explained. When a model developed from one subregion was applied to other subregions, we found over- or underestimations significant. Sometimes, in order to know how well a model from one subregion will perform when it is used in a different subregion, the calculated percent prediction error can be used as a criterion for estimating as an approximation. The percent prediction error can serve as an accurate indicator to determine the applicability of a fitted model. It is possible to create an acceptable $\overline{\mathrm{e}} \%$ according to the prediction intervals or select voluntarily without taking into account any statistical test, but it will have to depend on the required accuracy and available resources. The height-diameter models from several subregions may be used interchangeably for the height-diameter models, if $\mathrm{a} \pm 5 \%$ average bias for height predictions is enabling.

Figure 3 shows the height-diameter performance when each subregional model is applied to predict tree height separately in each of the ten subregions. Compared to the overall and region models, the subregional model more closely followed the actual values for all subregions and indicated that subregional height-diameter model should be needed.
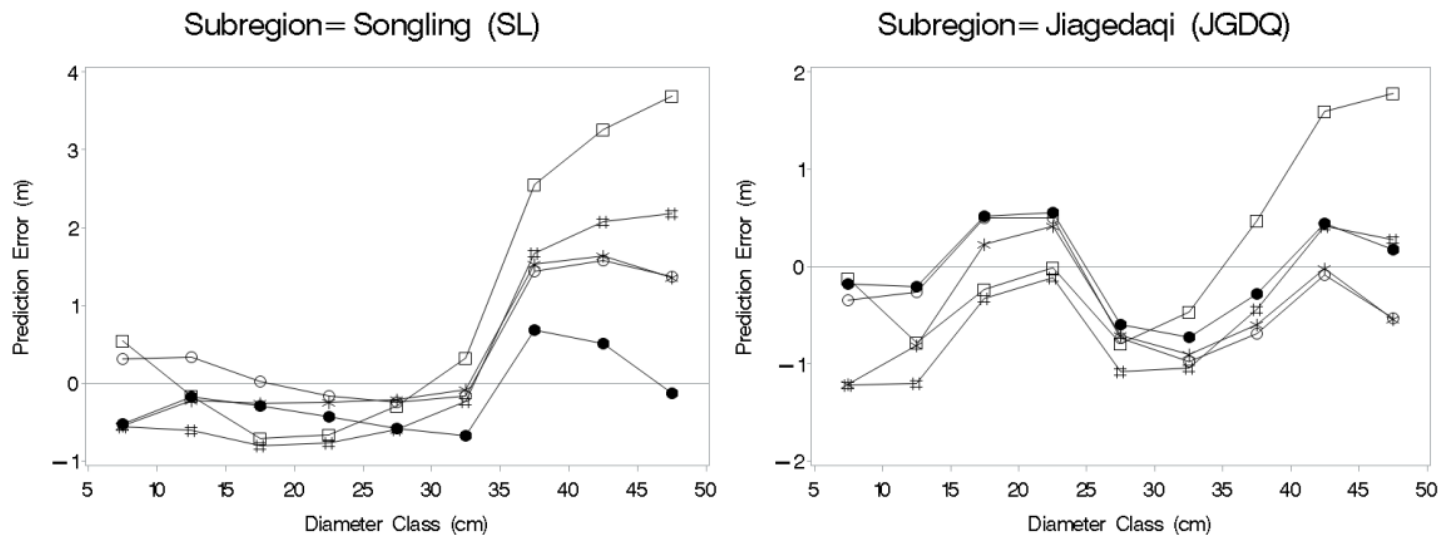


$$
-13581 \text { - }
$$

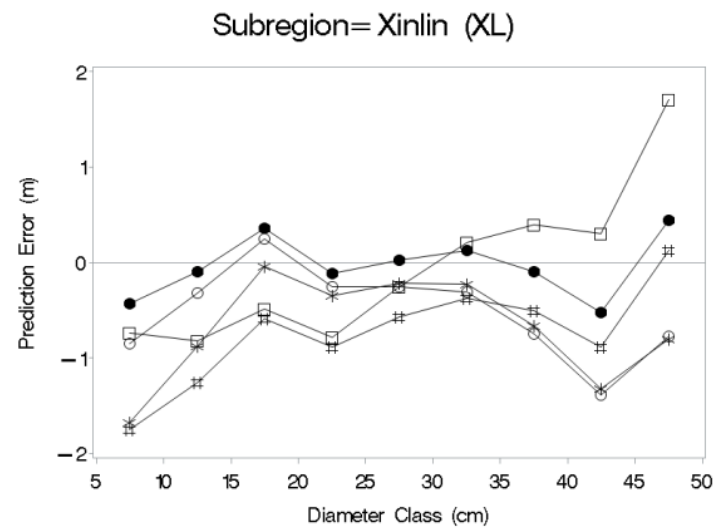

Subregion= Huzhong $(H Z)$

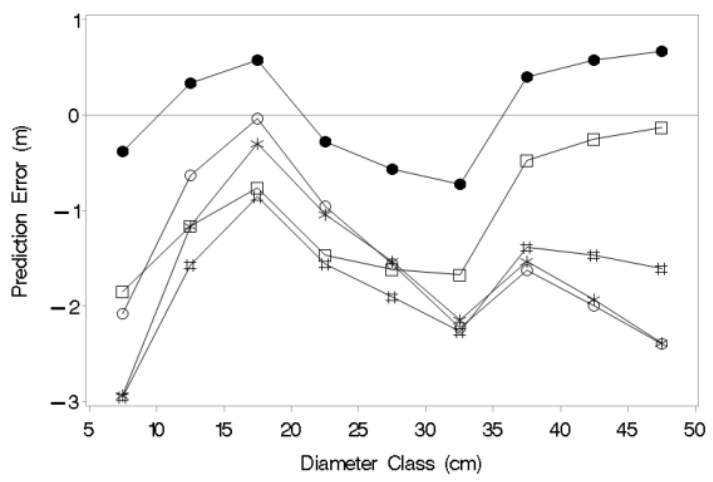

Subregion= Hanjiayuan (HJY)

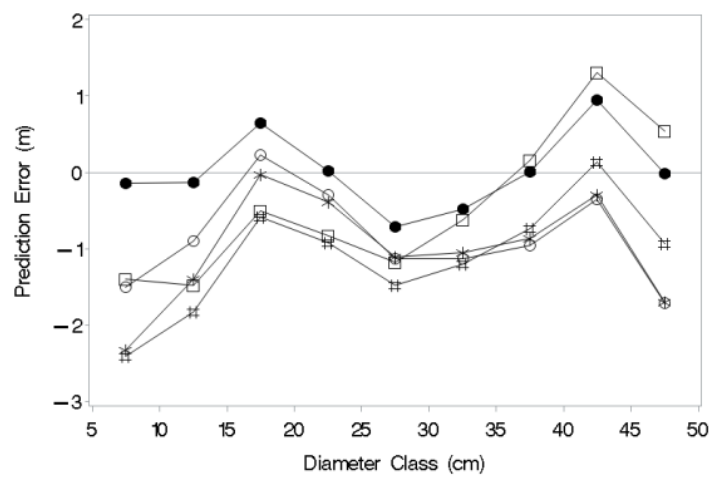

Subregion= Tuqiang (TQ)

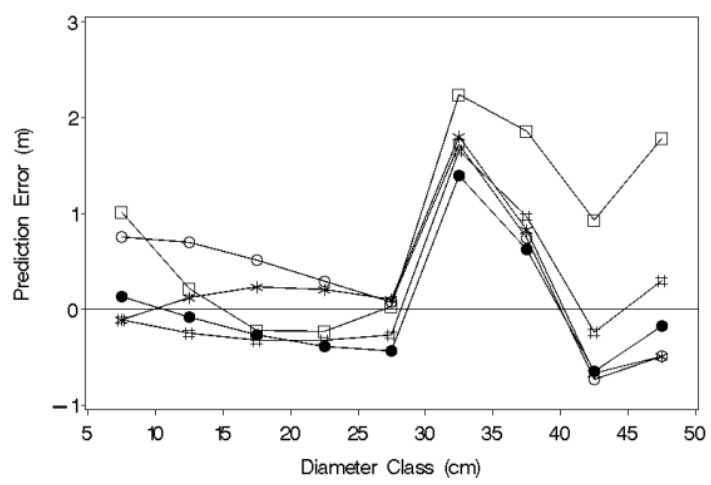

Subregion $=$ Tahe $(\mathrm{TH})$

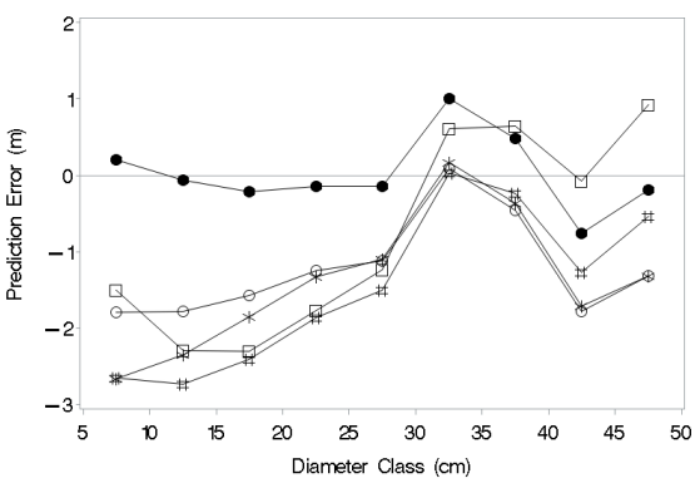

Subregion $=$ Shibazhan $($ SBZ)

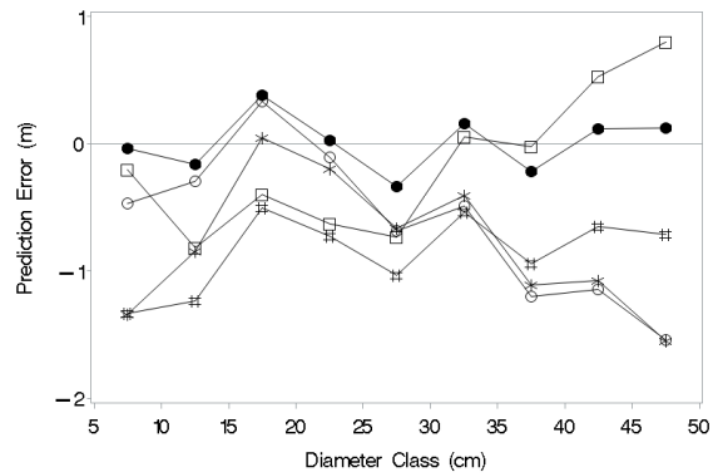

Subregion $=$ Xilinji $(X L J)$

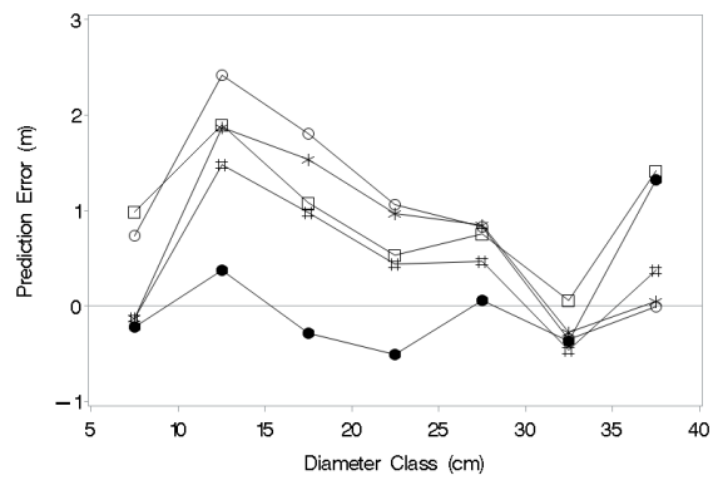

Subregion= Amuer $(\mathrm{AME})$

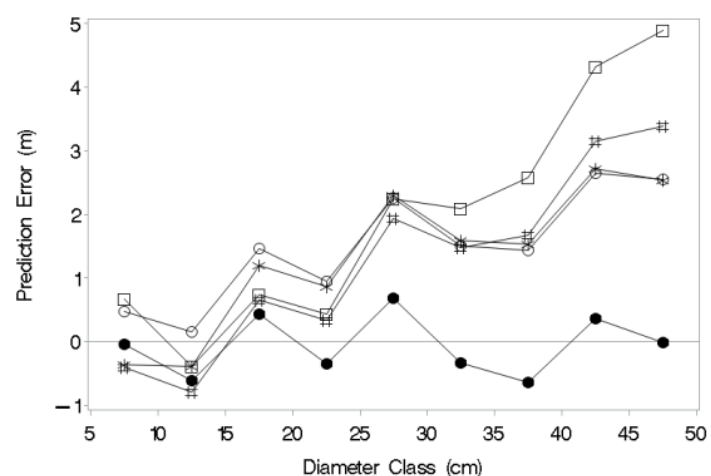

Figure 2. Average prediction errors $(\mathrm{m})$ across 5-cm diameter classes when the NDXAM, NWYLHLM, SAYLHLM regional models and the Overall model are applied to predict tree heights in each of the ten subregions. The overall and the subregion model with symbols NDXAM (hash), NWYLHLM (square), SAYLHLM (star), Overall (circle) and Subregion (dot) 


\section{Subregion= Songling (SL)}
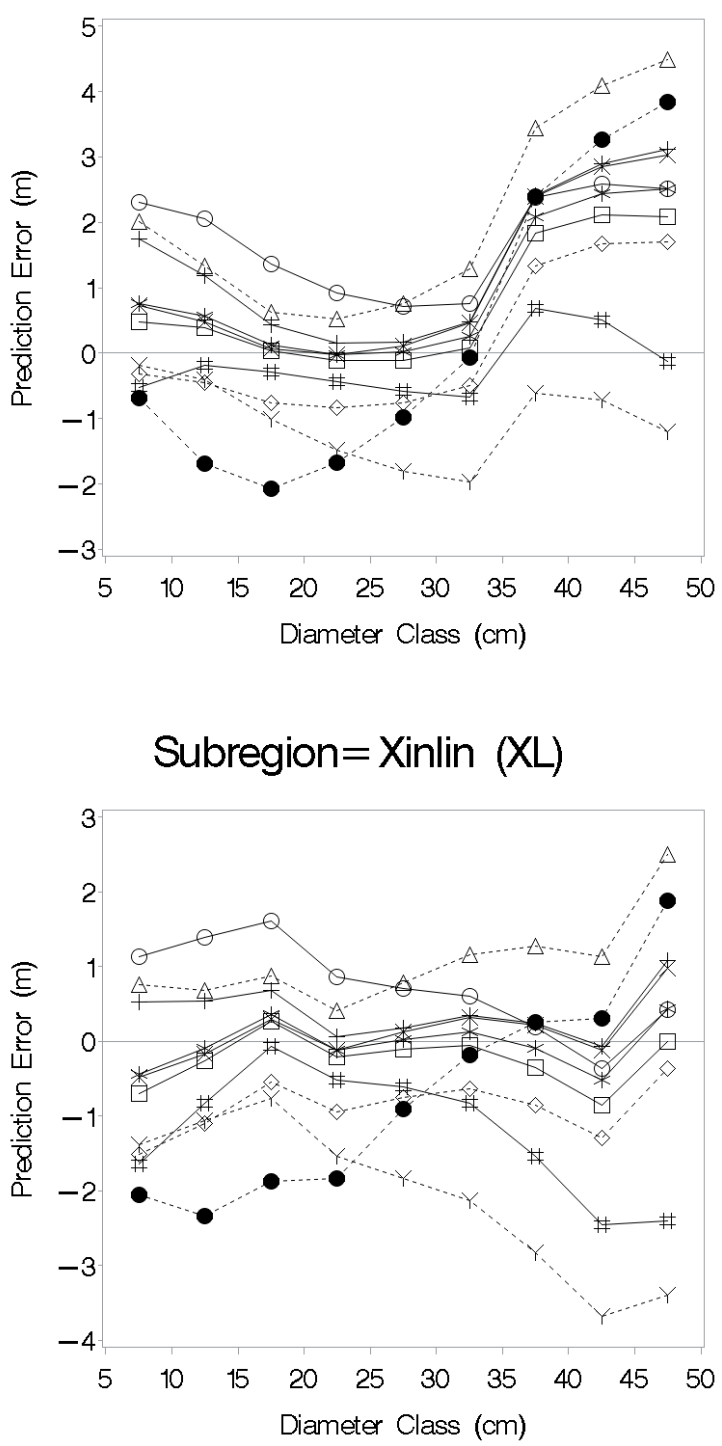

Subregion= Huzhong $(\mathrm{HZ})$

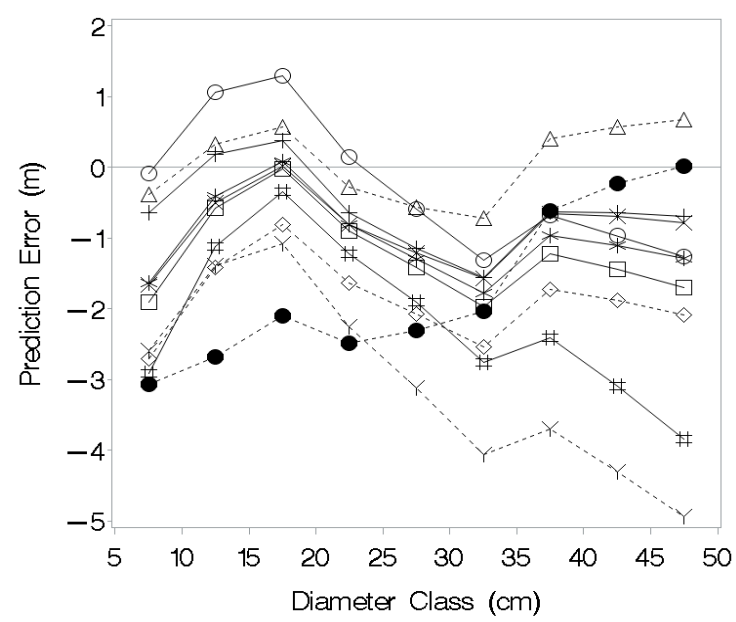

Subregion $=$ Jiagedaqi $(J G D Q)$

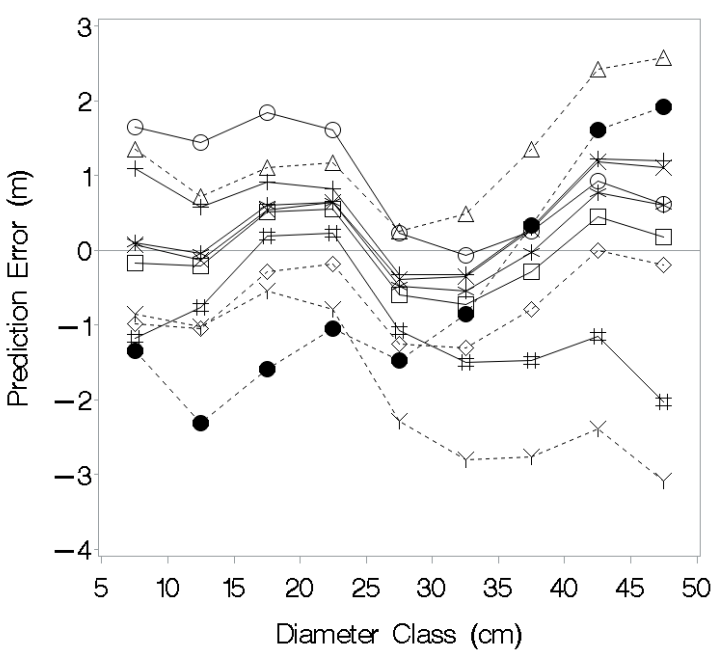

Subregion $=$ Tahe $(\mathrm{TH})$

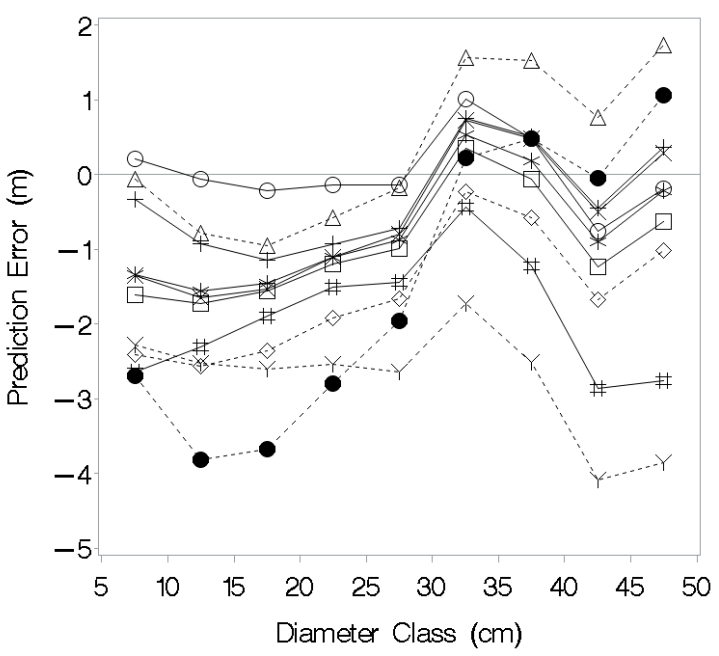

Subregion $=$ Shibazhan $(\mathrm{SBZ})$

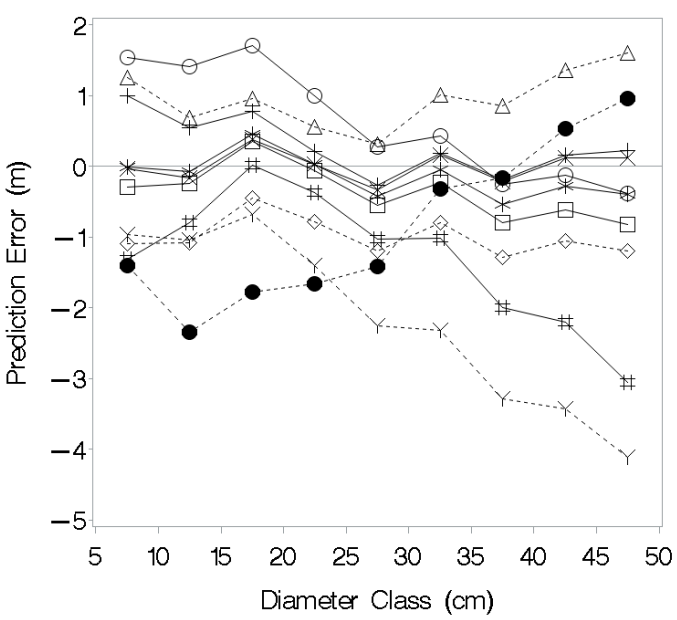




\section{Subregion= Hanjiayuan (HJY)}
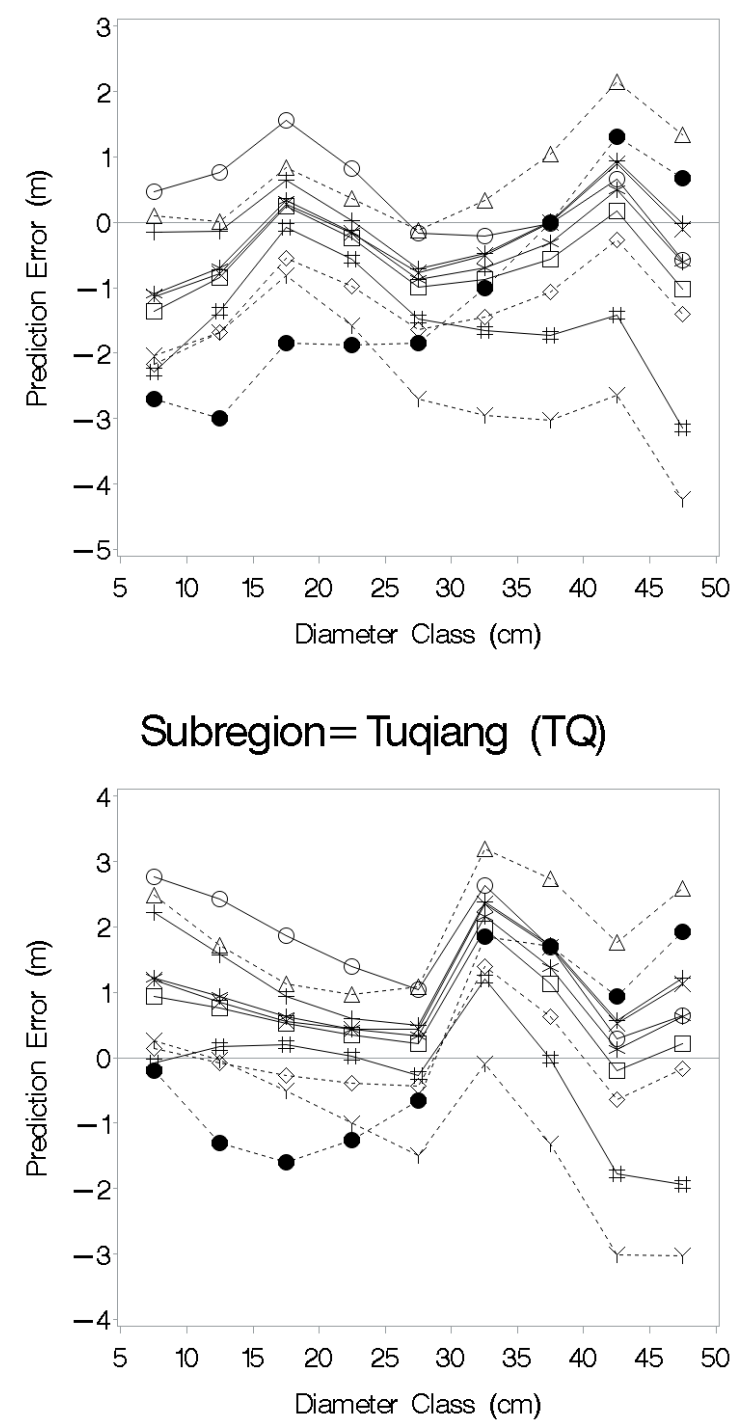

Subregion=Xilinji (XLJ)

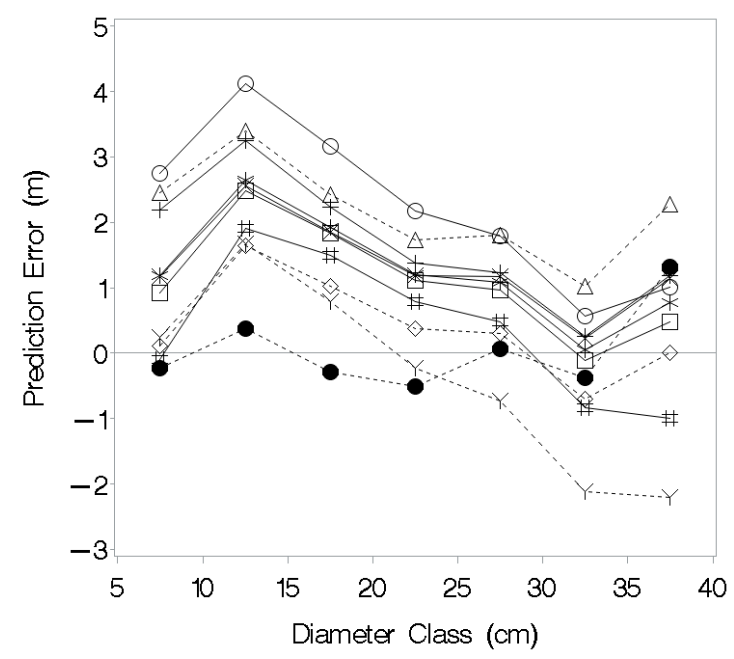

Subregion $=$ Amuer $(\mathrm{AME})$

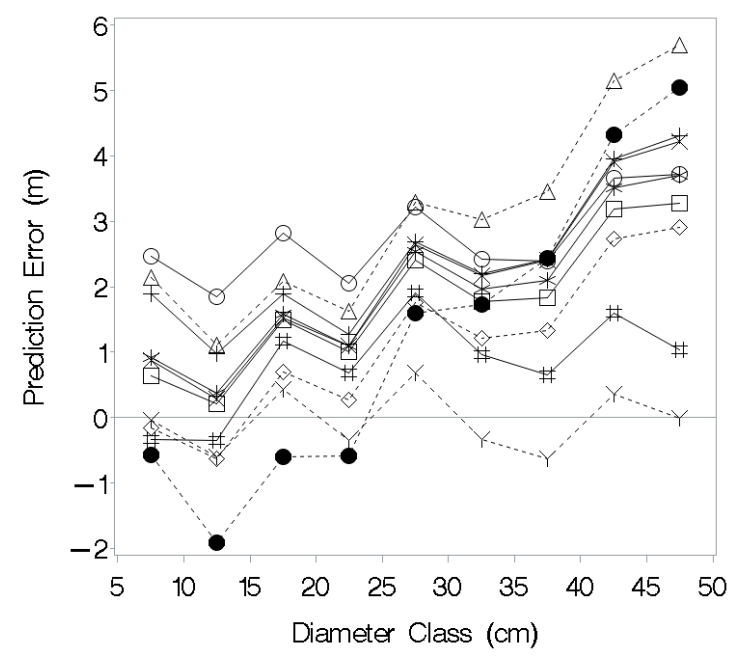

Figure 3. Average prediction errors $(m)$ across 5-cm diameter classes when each subregional model is applied to predict tree heights in each of the ten subregions with symbols: SL (hash), $J G D Q$ (square), XL (star), TH (circle), SBZ (X), HJY (plus), HZ (triangle), XLJ (dot), TQ (diamond) and $A M E(Y)$

In the forest literature, there is a high number of local and generalized heightdiameter equations available (Gadow et al., 2001; Soares and Tomé, 2002; Lopéz et al., 2003; Temesgen and Gadow, 2004; Brooks and Wiant, 2007; Stankova et al., 2013; Xu et al., 2014; Zhao et al., 2013; Adamec et al., 2015; Hassanzad et al., 2016; Yan-qiong et al., 2015). 30 nonlinear growth functions were fitted to a species of trees and 10 subregions in the Daxing'an Mountain at northeast China, based on their appropriate mathematical features and possible biological interpretation of parameters. The results from model statistics suggested that all thirty models fitted equally well to the tree height-diameter data of the species and the best is Chapman-Richards model. The analysis reveals that the height-diameter relationship is statistically different between the subregions identified in the current study. This was waited because biogeoclimatic 
conditions are not identical among different subregions. A climatic division is formed between the mountains, they differ from the arid region to the west as a result of the precipitation they take from the southeast winds and create a relatively humid climate (precipitation is more than 20 inches [500 mm] annually). The coldest part of eastern China is the northern mountain region with very rigorous winters (mean temperature $18{ }^{\circ} \mathrm{F}\left[-28{ }^{\circ} \mathrm{C}\right]$ ) and large areas under permafrost. With January temperatures approximately $-21^{\circ} \mathrm{C}$, annual rainfall of $10-12$ inches $(250-300 \mathrm{~mm})$ and light relative snowfall, the southern region of the range is much warmer and drier than in the north. To the south, forests cover the higher ground above 5,000 feet $(1500 \mathrm{~m})$, while the highest meadows cover most of the area (https://www.britannica.com/editor/the-editorsof encyclopedia-Britannica/4419: Mountains China). But the rapidity and the characteristics of its growth are affected by the unique features of the subregions. It was revealed that, Dahurian larch height-diameter relationships showed the differences among these subregions. The using of separate height-diameter models for NWYLHLM, SAYLHLM and NDXAM regions; likewise, because of the singular characteristics of the subregions in landforms, geology, vegetation, and climate separate height-diameter relationships for the Xilinji (XLJ), Tuqiang (TQ), Amuer (AME), Huzhong (HZ), Xinlin (XL), Tahe (TH), Shibazhan (SBZ), Hanjiayuan (HJY), Songling (SL), Jiagedaqi (JGDQ), all are provable, as this is shown from the F-test results in Tables 6, 7 and 8. Therefore, the combination of all climatic, environmental and vegetation factors plays an important role in determining the different height-diameter relationships among ten subregions. Subsequent F- tests suggest that the heightdiameter equation for the combined subregions $(\mathrm{XL}+\mathrm{SBZ}+\mathrm{HJY})$ is different from those for SL, JGDQ, TH, HZ, XLJ, TQ and AME subregions (Table 7). Therefore, according to the F-tests, eight height-diameter equations relating to eight distinctly different subregion groups were separated. Analyzing of the subregion-based heightdiameter models for Dahurian larch in Daxing'an Mountain suggested that the heightdiameter relationships for XL, SBZ, and HJY subregions are statistically the same. The sameness of height-diameter patterns between XL, SBZ and HJY subregions is probably due to the similarity in habitats that stands of Dahurian larch.

It is apparent from Table Al (Appendix) outcome of the calculated $\overline{\mathrm{e}}, \mathrm{Se}$, and $\overline{\mathrm{e}} \%$. It is demonstrated by examples values over and underestimated when the height-diameter equation from XLJ was served to predict the tree height in subregion AME 10.28\% underestimate appeared. Relatively, the value of $\overline{\mathrm{e}}$ was 2.29 and for Se was equal to 2.95. When the height-diameter equation from subregion XLJ was served to predict the tree height in subregion $\mathrm{TH},-14.2 \%$ an overestimate was observed. Carefully, the prediction errors values of $\overline{\mathrm{e}}$ and Se were $-2.17 \%$ and $2.48 \%$. Globally, the percent prediction error varies from $16.69 \%$ an underestimate to $-16.5 \%$ overestimate. The mean prediction errors vary from an underestimate of 3.73 (HZ applied to AME) to overestimate of 2.66 (AME applied to HZ). The paired t-test procedure outlined in Snedecor and Cochran (1989) was used to calculate the t-values of the mean prediction biases. It was revealed that significant over- or underestimations appeared when a model developed from one subregion was used to other subregions.

Founded on development data, we observed that the best-fitting model was the Chapman Richards model, which gives the most precise estimates with MSE values from 2.1909 to 4.5703 for all subregions (Table 5). When we fitted the Korf equation in each subregion, we found that this equation produced a largest parameter asymptotic, which is means the Korf equation doesn't have stability. This characteristic of the Korf 
function was also observed in Cross-validation of Non-linear Growth Functions (Zhang, 1997). The Chapman-Richards function was used to describe the height-diameter in several previous studies. Huang et al. (1992) declared that, when there is a weak relationship between the dependent and independent variables, this function approaches the asymptote too quickly. In this study, we found that the Chapman Richards model as the best for Dahurian larch produced some of the most satisfactory fits among many alternative model forms, considering the model mathematical features, biological interpretation of parameters, and accurate prediction. However, the performance of models, such as the Weibull, Schnute, Exponential and others was also very good. Comparing the model root mean squared errors (RMSE), the Richards, Korf and Weibull functions had relatively smaller RMSEs than the other twenty seven equations (Table 4).

\section{Conclusion}

Our study results suggest that there are distinct variations in height-diameter relationships for Dahurian larch among different subregions in the three forest regions (NDXAM, YLHLM-NW, and YLHLM-SA) in Daxing'an Mountain at northeast China. Usually, ecoregion-based height-diameter models report predictions with more reliability on a regional basis and avoid the likely expected errors that may arise while models are enforced in others areas. However, at any location where the data is favorable, it is advisable to develop different models by different ecoregions.

Acknowledgements. This research was financially supported by the National Natural Science Foundation of China (31570624), Applied Technology Research and Development Plan Project of Heilongjiang Province (GA19C006), and Fundamental Research Funds for Central Universities.

Conflict of interests. The authors declare that they have no conflict of interests.

\section{REFERENCES}

[1] Adamec, Z., Drápela, K. (2015): Generalized additive models as an alternative approach to the modelling of the tree height-diameter relationship. - J. For. Sci. 61: 235-243.

[2] Bates, D. M., Watts, D. G. (1980): Relative curvature measures of nonlinearity. - J. Roy. Stat. Soc. B, 42: 1-16.

[3] Bates D. M., Watts, D. G. (1988): Nonlinear Regression Analysis and Its Applications. Wiley, New York.

[4] Botkin, D. B., Janak, J. F., Wallis, J. R. (1972): Some ecological consequences of a computer model of forest growth. - The Journal of Ecology 849-872.

[5] Brooks, J. R., Wiant, H. V. (2007): Evaluating Ecoregion-Based Height-Diameter Relationship of Five Economically Important Appalachian Hardwood Species in West Virginia. - In: Mc Roberts, R. E., Reams, G. A., Van Deusen, P. C., McWilliams, W. H. (eds.) Proceedings of the Seventh Annual Forest Inventory and Analysis Symposium, 3-6 October, Portland, OR.

[6] Buford, M. A. (1986): Height-diameter relationship at age 15 in loblolly pine seed sources. - For. Sci. 32: 812-818.

[7] Burkhart, H. E., Strub, M. R. (1974): A Model for Simulation of Planted Loblolly Pine Stands. - In: Fries, J. (ed.) Growth Models for Tree and Stand Simulation. Royal College of Forestry, Stockholm, pp. 128-135. 
[8] Castedo-Dorado, F., Anta, M. B., Parresol, B. R., Gonzalez, J. G. A. (2005): A stochastic height-diameter model for maritime pine ecoregions in Galicia (Northwestern Spain). Ann Forest Science 62: 455-465.

[9] Corral-Rivas, J. J., Álvarez González, J. G., Ruiz, A. D., Gadow, K. V. (2004): Compatible height and site index models for five pine species in El Salto, Durango (Mexico). - Forestry Ecology Management 201: 145-160.

[10] Corral-Rivas, J. J., Diéguez-Aranda, U., Castedo, F., Corral, S. A. (2007): Merchantable volume system for major pine species in El Salto, Durango (Mexico). - Forestry Ecology Management 238: 118-129.

[11] Curtis, R. O. (1967): Height-diameter and height-diameter-age equations for secondgrowth Douglas-fir. - Forest Science 13: 365-375.

[12] Cutini, A., Chianucci, F., Manetti, M. C. (2013): Allometric relationships for volume and biomass for stone pine (Pinus pinea L.) in Italian coastal stands. - iForest 6: 331-337.

[13] Dai, Z. D., Jiang, L. C. (2015): Ecoregion based height-diameter models for Larix gmelinii Rupr in Daxing'an' Mountains. - Bulletin of Botanical Research 35(4): 583-589 (in Chinese).

[14] Fang, Z., Bailey, R. (1998): Height-diameter models for tropical forests on Hainan Island in southern China. - Forest Ecology and Management 110: 315-327.

[15] Farr, W. A., DeMars, D. J., Dealy, J. E. (1989): Height and crown width related to diameter for open-grown western hemlock and Sitka spruce. - Can. J. For. Res. 19: 12031207.

[16] Gadow, K. Real, P., Álvarez Gonzáles, J. G. (2001): Modelización del Crecimiento y la Evolución de los Bosques. - IUFRO World Series, Vol. 12, Vienna.

[17] Hassanzad, I., Navroodi, Alavi, S. J., Ahmadi, M. K., Radkarimi, M. (2015): Comparison of different non-linear models for prediction of the relationship between diameter and height of velvet maple trees in natural forests (case study: Asalem Forests, Iran). Journal of Forest Science 62(2): 65-71.

[18] Huang, S. (1999): Ecoregion-based individual tree height-diameter models for lodgepole pine in Alberta. - Western Journal of Applied Forestry 14: 186-193.

[19] Huang, S., Titus, S. J. (1992): Comparison of nonlinear height-diameter functions for major Alberta tree species. - Canada Forestry Resources 22(9): 1297-1304.

[20] Huang, S., Titus, S. J. (1994): An age-independent individual tree height prediction model for boreal spruce-aspen stands in Alberta. - Canadian Journal of Forest Research 24: 1295-1301.

[21] Huang, S., Price, D., Morgan, D., Titus, S. (1999): Validation of ecoregion-based taper equations for white spruce in Alberta. - The Forestry Chronicle 75: 281-292.

[22] Huang, S., Price, D., Titus, S. J. (2000): Development of ecoregion-based heightdiameter models for white spruce in boreal forests. - Forest Ecology and Management 129: $125-141$.

[23] Henricksen, H. A. (1950): Height-diameter curve with logarithmic diameter. - Dansk Skovforen. Tidsskr. 35: 193-202.

[24] Institute SAS (1999): SAS/STAT user's Guide, Version 8. - SAS Institute, Cary, NC.

[25] Jiang, Y., Zhang, J., Han, S., Chen, Z., Setälä, H., Yu, J., Zheng, X., Guo, Y., Gu, Y.(2016): Radial growth response of Larix gmelinii to climate along a latitudinal gradient in the greater Khingan Mountains. - Northeastern China Forests 7: 295.

[26] Larson, B. C. (1986): Development and growth of even-aged stands of Douglas-fir and grand fir. - Can. J. For. Res. 16: 367-372.

[27] Leng, W., He, H. S., Bu, R., Dai, L., Hu, Y., Wang, X. (2008): Predicting the distributions of suitable habitat for three larch species under climate warming in Northeastern China. - Forest Ecology and Management 254: 420-428.

[28] Loetsch, F., ZoÈhrer, F., Haller, K. E. (1973): Forest Inventory. Vol. 2. - BLV Verlagsgesellschaft mbH, München. 
[29] Lopéz, Sánchez, C. A., Gorgoso, J. J., Castedo, F., Rojo, A., Rodríguez, R., Álvarez González, J. G., Sánchez Lynch, T. B., Murphy, P. A. (2003): A compatible height prediction and projection system for individual trees in natural, even-aged shortleaf pine stands. - For Sci 41: 194-209.

[30] Meyer, H. A. (1940): A mathematical expression for height curves. - J. For. 38: 415-420.

[31] Moffat, A. J., Matthews, R. W., Hall, J. E. (1991): The effects of sewage sludge on growth and foliar and soil chemistry in pole-stage Corsican pine at Ringwood Forest, Dorset, UK. - Can. J. For. Res. 21: 902-909.

[32] Özçelik, R., Yavuz, H., Karatepe, Y., Gürlevik, N., Kiri, Ş. R. (2014): Development of ecoregion-based height-diameter models for 3 economically important tree species of southern Turkey. - Turkish Journal of Agriculture and Forestry 38: 399-412.

[33] Pearl, R., Reed, L. J. (1920): On the rate of growth of the population of the United States since 1970 and its mathematical representation. - Proc. Natl. Acad. Sci. U.S.A. 6: 275288.

[34] Peng, C., Zhang, L., Liu, J. (2001): Developing and validating nonlinear height-diameter models for major tree species of Ontario's boreal forests. - Northern Journal of Applied Forestry 18: 87-94.

[35] Peng, C., Zhang, L., Zhou, X., Dang, Q., Huang, S. (2004): Developing and evaluating tree height-diameter models at three geographic scales for black spruce in Ontario. Northern Journal of Applied Forestry 21: 83-92.

[36] Peng, C. H. (1999): Nonlinear height-diameter models for nine boreal forest tree species in Ontario. - Forest Research Report. Ontario Forest Research Institute, Marie, ON, Canada.

[37] Pillsbury, N. H., McDonald, P. M., Simon, V. (1995): Reliability of Tanoak volume equations when applied to different areas. - Western Journal of Applied Forestry 10: 7278.

[38] Prodan M (1968): Forest Biometrics (English Ed.). - Pergamon Press, Oxford (German ed. 1961).

[39] Ratkowsky, D. A. (1990): Handbook of Nonlinear Regression. - Marcel Dekker, Inc., New York.

[40] Ratkowsky, D. A., Reedy, T. J. (1986): Choosing near-linear parameters in the fourparameter logistic model for radio ligand and related assays. - Biometrics 42: 575-582.

[41] Richards F (1959): A flexible growth function for empirical use. - Journal of Experimental Botany 10: 290-301.

[42] Seber, G. A. F., Wild, C. J. (1989): Nonlinear Regression. - John Wiley and Sons, New York.

[43] Sibbesen E (1981): Some new equations to describe phosphate sorption by soils. European Journal of Soil Science 32: 67-74.

[44] Snedecor, G. W., Cochran, W. G. (1989): Statistical Methods. Eighth Ed. - Iowa State University, Ames, IA.

[45] Soares, P., Tomé, M. (2002): Height-diameter equation for first rotation eucalypt plantations in Portugal. - Forest Ecology Management 166: 99-109.

[46] Stage, A. R. (1975): Prediction of height increment for models of forest growth. - USDA For. Serv. Res. Pap. INT-164.

[47] Stankova, T. V., Diéguez-Aranda, U. (2013): Height-diameter relationships for Scots pine plantation in Bulgaria: optimal combination of model type and application. - Ann For Res 56: 149-163.

[48] Stoffels, A., van Soest, J. (1953): The main problems in sample plots. 3. height regression. - Ned Bosbouwtijdschr. 25: 190-199 (English summary in For. Abstr. 15: 77).

[49] Tang, S. (1994): Self-adjusted height-diameter curves and one entry volume model. Forest Research 7(5): 512-518 (in Chinese). 
[50] Temesgen, H., Gadow, K. V. (2004): Generalized height-diameter models an application for major tree species in complex stands of interior British Columbia. Europe. - Journal Forests Resources 123: 45-51.

[51] Watts, S. B. (1983): Forestry Handbook for British Columbia. 4th Ed. - Forestry Undergraduate Society, Vancouver, B.C.

[52] Winsor, C. P. (1932): The Gompertz curve as a growth curve. - Proc. Natl. Acad. Sci. U.S.A. 18: 1-7.

[53] Wykoff, W. R., Crookston, N. L., Stage, A. R. (1982): User's Guide to the Stand Prognosis Model. - Intermountain Forest and Range Experiment Station, Ogden, UT.

[54] Xu, H., Sun, Y., Wang, X., Fu, Y., Dong, Y., Li Y (2014): Nonlinear mixed-effects (NLME) diameter growth models for individual China-fir (Cunninghamia lanceolata) trees in southeast China. - PLoS One 9: e104012. DOI: 10.1371/journal.pone.0104012 PMID: 25084538.

[55] Yan-qiong, L., et al. (2015): Development and evaluation of models for the relationship between tree height and diameter at breast height for Chinese-fir plantations in subtropical China. - PLoS One 10(4): e0125118. DOI: 10.1371/journal.pone.0125118.

[56] Yang, R. C., Kozak, A., Smith, J. H. G. (1978): The potential of Weibull-type functions as flexible growth curves. - Canadian Journal of Forest Research 8: 424-431.

[57] Zhang, H., Lei, X., Zeng, W. (2016): Height-diameter equations for larch plantations in northern and northeastern China: a comparison of the mixed-effects, quantile regression and generalized additive models. - Forestry 89: 434-445.

[58] Zhang, L. (1997): Cross-validation of non-linear growth functions for modelling tree height- diameter relationships. - Annals of Botany 79: 251-257.

[59] Zhang, L., Peng, C., Huang, S., Zhou, X. (2002): Development and evaluation of ecoregion-based jack pine height-diameter models for Ontario. - The forestry Chronicle 78: 530-538.

[60] Zhang, W. R., Sheng, W. T., Jiang, Y. X., Zhou, Z. X., Wang, X. S. (1992): Classification of forest site system in China. - Forest Research 5(3): 251-262 (in Chinese).

[61] Zhao, M. F., Xiang, W. H., Tian, D. L., Deng, X. W., Huang, Z. H., Zhou, X. L., et al. (2013): Effects of increased nitrogen deposition and rotation length on long-term productivity of Cunninghamia lanceolata plantation in southern China. - PLoS One 8(2): e55376. doi: 10.1371/journal.pone.0055376 PMID: 23390533.

[62] Zeide, B. (1989): Accuracy of equations describing diameter growth. - Can. J. For. Res. 19:1283-1286.

[63] Zeide, B. (1993): Analysis of growth equations. - For. Sci. 39(3): 594-616.

\section{APPENDIX}

Table A1. Prediction errors of applying a specific subregion model to each subregion

\begin{tabular}{c|c|c|c|c|c|c|c|c}
\hline Subregion & $\mathbf{N}$ & $\overline{\mathbf{H}}(\mathbf{m})$ & $\hat{\mathbf{H}}(\mathbf{m})$ & $\overline{\mathbf{e}}$ & $\overline{\mathbf{e}} \%$ & $\mathbf{S e}$ & $\mathbf{t}$ & $\mathbf{p}$-value \\
\hline Songling model & & & & & & & & \\
SL-SL & 214 & 19.58 & 19.57 & 0.01 & 0.06 & 1.68 & 0.1149 & 0.9085 \\
SL-JGDQ & 524 & 18.29 & 19.02 & -0.72 & -3.95 & 2.26 & -7.3121 & $<0.0001$ \\
SL-XL & 190 & 19.33 & 20.42 & -1.09 & -5.64 & 2.03 & -7.3741 & $<0.0001$ \\
SL-TH & 203 & 15.34 & 17 & -1.66 & -10.84 & 1.97 & -12.1121 & $<0.0001$ \\
SL-HZ & 215 & 16.12 & 17.74 & -1.62 & -10.06 & 2.17 & -10.9611 & $<0.0001$ \\
SL-SBZ & 237 & 17.93 & 19.04 & -1.11 & -6.21 & 2.09 & -8.1781 & $<0.0001$
\end{tabular}




\begin{tabular}{|c|c|c|c|c|c|c|c|c|}
\hline SL-HJY & 128 & 17.72 & 18.96 & -1.24 & -7.004 & 2.09 & -6.7131 & $<0.0001$ \\
\hline SL-XLJ & 224 & 15.75 & 14.61 & 1.15 & 7.32 & 1.76 & 9.7611 & $<0.0001$ \\
\hline SL-TQ & 191 & 17.44 & 17.49 & -0.3 & -1.72 & 1.86 & -2.2211 & 0.0273 \\
\hline SL-AME & 285 & 22.36 & 21.24 & 1.12 & 5.02 & 1.91 & 9.9303 & $<0.0001$ \\
\hline \multicolumn{9}{|c|}{ Jiagedaqi model } \\
\hline JGDQ-SL & 214 & 19.58 & 18.69 & 0.88 & 4.53 & 1.89 & 6.8569 & $<0.0001$ \\
\hline JGDQ-JGDQ & 524 & 18.29 & 18.32 & -0.06 & -0.03 & 2.13 & -0.0691 & 0.9446 \\
\hline JGDQ-XL & 190 & 19.33 & 19.56 & -0.22 & -1.15 & 1.79 & -1.7174 & 0.0875 \\
\hline JGDQ-TH & 203 & 15.34 & 16.51 & -1.17 & -7.64 & 1.94 & -8.5851 & $<0.0001$ \\
\hline JGDQ-HZ & 215 & 16.12 & 17.25 & -1.13 & -7.02 & 1.97 & -8.3971 & $<0.0001$ \\
\hline JGDQ-SBZ & 237 & 17.93 & 18.33 & -0.36 & -2.04 & 1.83 & -3.0661 & 0.0024 \\
\hline JGDQ-HJY & 128 & 17.72 & 18.32 & -0.6 & -3.38 & 1.9 & -3.5661 & 0.0005 \\
\hline JGDQ-XLJ & 224 & 15.75 & 14.31 & 1.45 & 9.21 & 1.62 & 13.3751 & $<0.0001$ \\
\hline JGDQ-TQ & 191 & 17.44 & 16.78 & 0.66 & 3.82 & 1.72 & 5.3497 & $<0.0001$ \\
\hline JGDQ-AME & 285 & 22.36 & 20.15 & 2.2 & 9.87 & 2.08 & 17.8962 & $<0.0001$ \\
\hline \multicolumn{9}{|l|}{ Xinlin model } \\
\hline XL-SL & 214 & 19.58 & 18.46 & 1.12 & 5.72 & 1.94 & 8.4179 & $<0.0001$ \\
\hline XL-JGDQ & 524 & 18.29 & 18.09 & 0.2 & 1.11 & 2.13 & 2.1867 & 0.0292 \\
\hline XL-XL & 190 & 19.33 & 19.33 & -0.01 & -0.07 & 1.79 & -0.0113 & 0.913 \\
\hline XL-TH & 203 & 15.34 & 16.32 & -0.98 & -6.4 & 1.95 & -7.1721 & $<0.0001$ \\
\hline XL-HZ & 215 & 16.12 & 17.07 & -0.95 & -5.89 & 1.96 & -7.1032 & $<0.0001$ \\
\hline XL-SBZ & 237 & 17.93 & 18.08 & -0.14 & -0.83 & 1.82 & -1.2612 & 0.209 \\
\hline XL-HJY & 128 & 17.72 & 18.12 & -0.4 & -2.27 & 1.89 & -2.4052 & 0.0176 \\
\hline XL-XLJ & 224 & 15.75 & 14.12 & 1.63 & 10.36 & 1.61 & 15.1591 & $<0.0001$ \\
\hline XL-TQ & 191 & 17.44 & 16.55 & 0.89 & 5.12 & 1.71 & 7.1867 & $<0.0001$ \\
\hline XL-AME & 285 & 22.36 & 19.91 & 2.46 & 11 & 2.13 & 19.4831 & $<0.0001$ \\
\hline \multicolumn{9}{|l|}{ Tahe model } \\
\hline TH-SL & 214 & 19.58 & 17.75 & 1.82 & 9.32 & 1.8 & 14.8481 & $<0.0001$ \\
\hline TH-JGDQ & 524 & 18.29 & 17.31 & 0.98 & 5.38 & 2.19 & 10.2822 & $<0.0001$ \\
\hline TH-XL & 190 & 19.33 & 18.71 & 0.62 & 3.24 & 1.86 & 4.6291 & $<0.0001$ \\
\hline TH-TH & 203 & 15.34 & 15.32 & 0.01 & 0.07 & 1.88 & 0.0922 & 0.9265 \\
\hline TH-HZ & 215 & 16.12 & 16.15 & -0.02 & -0.17 & 2.07 & -0.2123 & 0.8413 \\
\hline TH-SBZ & 237 & 17.93 & 17.32 & 0.61 & 3.41 & 1.96 & 4.8031 & $<0.0001$ \\
\hline TH-HJY & 128 & 17.72 & 17.32 & 0.39 & 2.21 & 1.94 & 2.2817 & $<0.0241$ \\
\hline TH-XLJ & 224 & 15.75 & 12.87 & 2.88 & 18.3 & 1.76 & 24.5241 & $<0.0001$ \\
\hline TH-TQ & 191 & 17.44 & 15.63 & 1.81 & 10.41 & 1.85 & 13.5143 & $<0.0001$ \\
\hline TH-AME & 285 & 22.36 & 19.38 & 2.98 & 13.34 & 1.95 & 25.7151 & $<0.0001$ \\
\hline \multicolumn{9}{|l|}{ Huzhong model } \\
\hline HZ-SL & 214 & 19.58 & 17.29 & 2.29 & 11.71 & 2.25 & 14.8871 & $<0.0001$ \\
\hline HZ-JGDQ & 524 & 18.29 & 17.02 & 1.27 & 6.96 & 2.21 & 13.1672 & $<0.0001$ \\
\hline HZ-XL & 190 & 19.33 & 18.19 & 1.13 & 5.89 & 1.86 & 8.4074 & $<0.0001$ \\
\hline HZ-TH & 203 & 15.34 & 15.37 & -0.02 & -0.18 & 2.06 & -0.1951 & 0.8454 \\
\hline HZ-HZ & 215 & 16.12 & 16.13 & -0.06 & -0.04 & 1.92 & 0.0495 & 0.9605 \\
\hline HZ-SBZ & 237 & 17.93 & 16.97 & 0.95 & 5.31 & 1.84 & 7.9651 & $<0.0001$ \\
\hline HZ-HJY & 128 & 17.72 & 17.12 & 0.61 & 3.46 & 1.92 & 3.6063 & 0.0004 \\
\hline HZ-XLJ & 224 & 15.75 & 13.23 & 2.52 & 16 & 1.57 & 23.9041 & $<0.0001$ \\
\hline
\end{tabular}




\begin{tabular}{|c|c|c|c|c|c|c|c|c|}
\hline HZ-TQ & 191 & 17.44 & 15.43 & 2.01 & 11.54 & 1.77 & 15.6723 & $<0.0001$ \\
\hline HZ-AME & 285 & 22.36 & 18.63 & 3.73 & 16.69 & 2.41 & 26.0481 & $<0.0001$ \\
\hline \multicolumn{9}{|c|}{ Shibazhan model } \\
\hline SBZ-SL & 214 & 19.58 & 18.28 & 1.3 & 6.63 & 2.06 & 9.2178 & $<0.0001$ \\
\hline SBZ-JGDQ & 524 & 18.29 & 18.32 & 0.29 & 1.58 & 2.2 & 3.0113 & 0.0027 \\
\hline SBZ-XL & 190 & 19.33 & 19.14 & 0.19 & 0.98 & 1.8 & 1.4579 & 0.1465 \\
\hline SBZ-TH & 203 & 15.34 & 16.25 & -0.91 & -5.97 & 2 & -6.5171 & $<0.0001$ \\
\hline SBZ-HZ & 215 & 16.12 & 16.99 & -0.86 & -5.38 & 1.94 & -6.5532 & $<0.0001$ \\
\hline SBZ-SBZ & 237 & 17.93 & 17.93 & 0.01 & 0.08 & 1.81 & 0.0136 & 0.9891 \\
\hline SBZ-HJY & 128 & 17.72 & 17.99 & -0.27 & -1.55 & 1.9 & -1.6311 & 0.1053 \\
\hline SBZ-XLJ & 224 & 15.75 & 14.13 & 1.62 & 10.29 & 1.57 & 15.3814 & $<0.0001$ \\
\hline SBZ-TQ & 191 & 17.44 & 16.44 & 1 & 5.77 & 1.72 & 8.0997 & $<0.0001$ \\
\hline SBZ-AME & 285 & 22.36 & 19.66 & 2.7 & 12.09 & 2.24 & 20.3611 & $<0.0001$ \\
\hline \multicolumn{9}{|c|}{ Hanjiayuan model } \\
\hline HJY-SL & 214 & 19.58 & 18.01 & 1.57 & 8.02 & 2 & 11.4452 & $<0.0001$ \\
\hline HJY-JGDQ & 524 & 18.29 & 17.66 & 0.62 & 3.43 & 2.15 & 6.6657 & $<0.0001$ \\
\hline HJY-XL & 190 & 19.33 & 18.95 & 0.38 & 1.97 & 1.8 & 2.9166 & 0.003 \\
\hline HJY-TH & 203 & 15.34 & 15.85 & -0.51 & -3.32 & 1.93 & -3.7491 & 0.0002 \\
\hline HJY-HZ & 215 & 16.12 & 16.65 & -0.52 & -3.28 & 1.95 & -3.9623 & 0.0001 \\
\hline HJY-SBZ & 237 & 17.93 & 17.64 & 0.28 & 1.59 & 1.84 & 2.3845 & 0.0178 \\
\hline HJY-HJY & 128 & 17.72 & 17.72 & -0.06 & -0.03 & 1.87 & -0.0362 & 0.9709 \\
\hline HJY-XLJ & 224 & 15.75 & 13.54 & 2.2 & 14 & 1.66 & 19.8661 & $<0.0001$ \\
\hline HJY-TQ & 191 & 17.44 & 16.01 & 1.43 & 8.21 & 1.76 & 11.2541 & $<0.0001$ \\
\hline HJY-AME & 285 & 22.36 & 19.49 & 2.87 & 12.85 & 2.17 & 22.3332 & $<0.0001$ \\
\hline \multicolumn{9}{|l|}{ Xilinji model } \\
\hline XJL-SL & 214 & 19.58 & 19.23 & 0.58 & 2.99 & 2.82 & 3.0329 & 0.002 \\
\hline XJL-JGDQ & 524 & 18.29 & 18.86 & -0.56 & -3.08 & 2.52 & -5.1112 & 0.0006 \\
\hline XJL-XL & 190 & 19.33 & 19.81 & -0.47 & -2.44 & 2.2 & -2.956 & 0.003 \\
\hline XJL-TH & 203 & 15.34 & 17.52 & -2.17 & -14.2 & 2.48 & -12.5232 & $<0.0001$ \\
\hline XJL-HZ & 215 & 16.12 & 18.18 & -2.05 & -12.75 & 2.06 & -14.5824 & $<0.0001$ \\
\hline XJL-SBZ & 237 & 17.93 & 18.76 & -0.83 & -4.63 & 2.08 & -6.1391 & $<0.0001$ \\
\hline XJL-HJY & 128 & 17.72 & 18.97 & -1.25 & -7.07 & 2.25 & -6.3312 & $<0.0001$ \\
\hline XJL-XLJ & 224 & 15.75 & 15.75 & -0.001 & -0.006 & 1.47 & -0.0113 & 0.991 \\
\hline XJL-TQ & 191 & 17.44 & 17.45 & -0.02 & -0.01 & 2.11 & -0.0142 & 0.989 \\
\hline XJL-AME & 285 & 22.36 & 20.06 & 2.29 & 10.28 & 2.95 & 13.1434 & $<0.0001$ \\
\hline \multicolumn{9}{|l|}{ Tuqiang model } \\
\hline TQ-SL & 214 & 19.58 & 19.31 & 0.27 & 1.39 & 1.96 & 2.0221 & 0.0443 \\
\hline TQ-JGDQ & 524 & 18.29 & 18.94 & -0.64 & -3.54 & 2.13 & -6.9321 & $<0.0001$ \\
\hline TQ-XL & 190 & 19.33 & 20.16 & -0.82 & -4.26 & 1.79 & -6.3132 & $<0.0001$ \\
\hline TQ-TH & 203 & 15.34 & 17.21 & -1.87 & -12.22 & 1.98 & -13.4612 & $<0.0001$ \\
\hline TQ-HZ & 215 & 16.12 & 17.94 & -1.81 & -11.28 & 1.96 & -13.6241 & $<0.0001$ \\
\hline TQ-SBZ & 237 & 17.93 & 18.93 & -1 & -5.57 & 1.82 & -8.4541 & $<0.0001$ \\
\hline TQ-HJY & 128 & 17.72 & 18.97 & -1.24 & -7.05 & 1.9 & -7.4122 & $<0.0001$ \\
\hline TQ-XLJ & 224 & 15.75 & 15.07 & 0.68 & 4.33 & 1.59 & 6.4182 & $<0.0001$ \\
\hline TQ-TQ & 191 & 17.44 & 17.45 & -0.04 & -0.02 & 1.71 & -0.0351 & 0.9717 \\
\hline TQ-AME & 285 & 22.36 & 20.72 & 1.64 & 7.35 & 2.15 & 12.8821 & $<0.0001$ \\
\hline
\end{tabular}




$$
-13591 \text { - }
$$

\begin{tabular}{c|c|c|c|c|c|c|c|c} 
Amuer model & & & & & & & & \\
AME-SL & 214 & 19.58 & 20.61 & -1.03 & -5.26 & 1.73 & -8.7121 & $<0.0001$ \\
AME-JGDQ & 524 & 18.29 & 20.08 & -1.78 & -9.76 & 2.31 & -17.7735 & $<0.0001$ \\
AME-XL & 190 & 19.33 & 21.57 & -2.23 & -11.57 & 2.03 & -15.1721 & $<0.0001$ \\
AME-TH & 203 & 15.34 & 17.95 & -2.61 & -17.02 & 1.92 & -19.2912 & $<0.0001$ \\
AME-HZ & 215 & 16.12 & 18.78 & -2.66 & -16.5 & 2.19 & -17.7521 & $<0.0001$ \\
AME-SBZ & 237 & 17.93 & 20.1 & -2.16 & -12.09 & 2.14 & -15.5414 & $<0.0001$ \\
AME-HJY & 128 & 17.72 & 20.05 & -2.33 & -13.19 & 2.08 & -12.7122 & $<0.0001$ \\
AME-XLJ & 224 & 15.75 & 15.37 & 0.38 & 2.44 & 1.82 & 3.1623 & 0.001 \\
AME-TQ & 191 & 17.44 & 18.38 & -0.93 & -5.353 & 2.04 & -6.3121 & $<0.0001$ \\
AME-AME & 285 & 22.36 & 22.368 & -0.02 & -0.01 & 1.88 & -0.0282 & 0.983 \\
\hline
\end{tabular}

$\mathrm{N}$ - sample size, $\overline{\mathrm{H}}-$ average of observed tree height, $\hat{\mathrm{H}}$ - average of predicted tree height from the model, $\overline{\mathbf{e}}-$ average of prediction error, $\overline{\mathrm{e}} \%$ - percent prediction error, $\mathrm{S}_{\mathrm{e}}-$ standard deviation of prediction error 